Document downloaded from:

http://hdl.handle.net/10251/155021

This paper must be cited as:

Arellano, LM.; Yue, S.; Atienzar Corvillo, PE.; Gómez-Escalonilla, MJ.; Ortega Higueruelo, FJ.; Fierro, JLG.; García Gómez, H... (2019). Modulating charge carrier density and mobility in doped graphene by covalent functionalization. Chemical Communications. 55(67):999910002. https://doi.org/10.1039/c9cc04571f

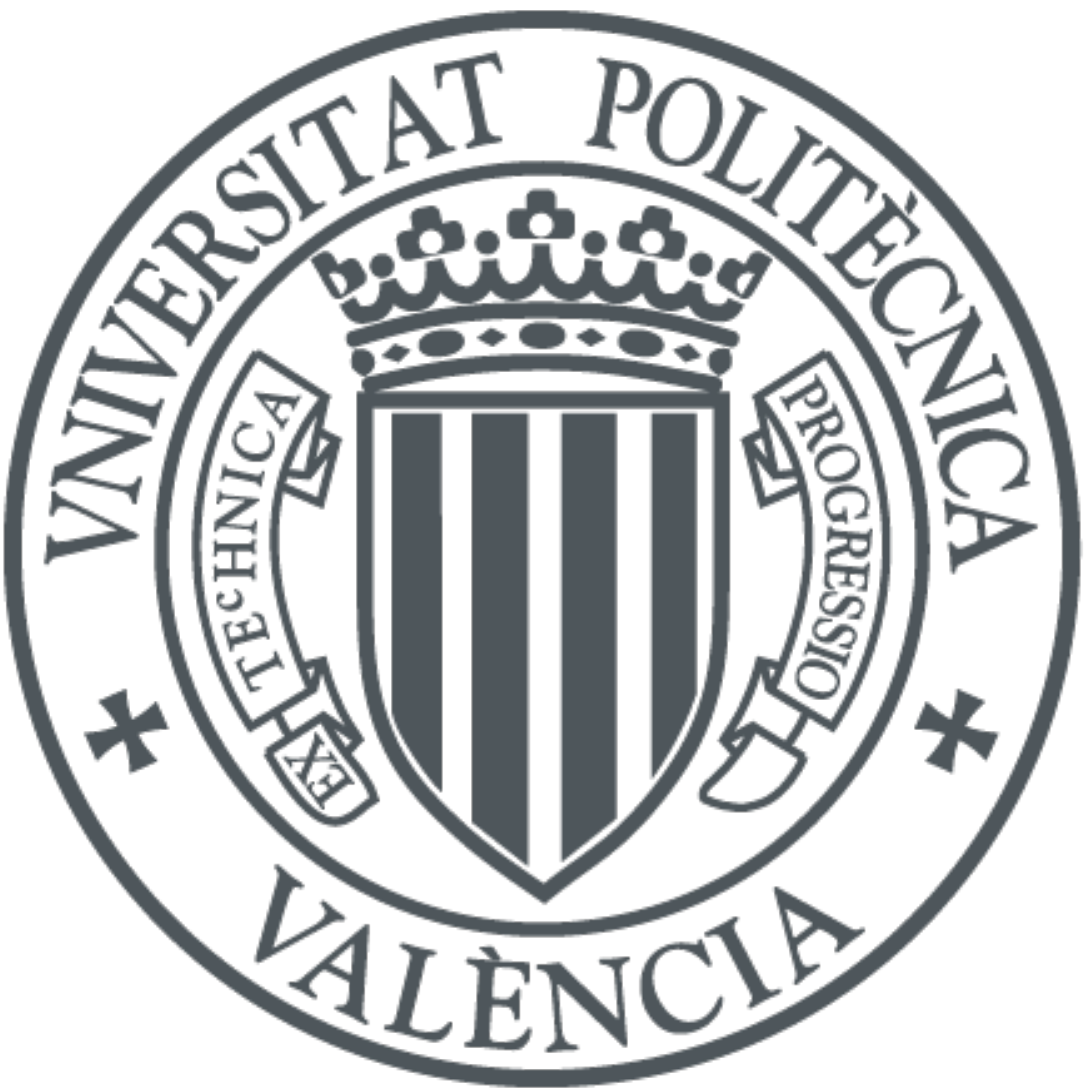

The final publication is available at

https://doi.org/10.1039/c9cc04571f

Copyright The Royal Society of Chemistry

Additional Information 


\section{Modulating Charge Carrier Density and Mobility in Doped Graphene by Covalent Functionalization}

Received 00th January 20xx, Accepted 00th January 20xx
Luis Miguel Arellano, ${ }^{a}$ Sun Yue, ${ }^{b}$ Pedro Atienzar, ${ }^{b}$ María J. Gómez-Escalonilla, ${ }^{a}$ Francisco J. OrtegaHigueruelo, a José Luis G. Fierro, ${ }^{c}$ Hermenegildo García*,b and Fernando Langa*,a

DOI: $10.1039 / \times 0 \times x 00000 x$

Covalent B-functionalization of B-graphene has been performed by the first time. Electronic properties and Hall effect of functionalized $\mathrm{N}$ - and B-graphene can be tuned by tailoring the electron-donating/-withdrawing properties of the organic addend.

One of the most important issues in the field of graphene for electronic and optoelectronic applications is how to modulate effectively the density of charge carriers, their mobility and their energy levels. One general strategy for achieving this goal is doping graphene with heteroatoms; ${ }^{1}$ in this approach, the properties of graphene are controlled by the nature of the dopant elements and by the percentage of doping. However, this strategy does have several limitations related to the small variety of dopant elements that have been reported to date. Nitrogen and boron are by far the most common dopant elements and graphenes doped with these heteroatoms have been widely used in electrocatalysis, as photocatalysts and as electronic materials. ${ }^{2-5}$ However, it would be convenient to develop additional tools to achieve further control of the electronic properties of graphene materials. In this context, one of the possibilities would be to functionalize those dopant elements on the graphene sheet in such a way that the electron density and electronegativity of the heteroatom is effectively controlled.

This objective could, in principle, be achieved by applying concepts from organic chemistry. Organic synthesis offers proven chemical reactions that are applicable to different types of nitrogen and boron compounds. The formation of new covalent bonds allows the electron density of these dopant atoms to be modified. In a simple strategy, electron-donating

\footnotetext{
a. Universidad de Castilla-La Mancha, Instituto de Nanociencia, Nanotecnología y Materiales Moleculares (INAMOL), 45071-Toledo, Spain. E-mail: Fernando.Langa@uclm.es

b. Instituto Universitario de Tecnología Química, CSIC-UPV, Universitat Politécnica de Valencia, 46022, Valencia, Spain.E-mail: hgarcia@qim.upv.es

c. Instituto de Catálisis y Petroleoquímica, CSIC, Cantoblanco, 28049, Madrid.

E-mail: ilgfierro@icp.csic.es

tElectronic Supplementary Information (ESI): Experimental and synthetic

procedures, along with Figs. S1-S12 and Tables S1-S5.See DOI: 10.1039/x0xx00000x
}

and -withdrawing groups present on aromatics rings can be used to modulate the electronic properties of the material.

In the work described here, covalent functionalization of the boron atom of B-doped graphene has been performed by the first time; moreover, electrical measurements based on the Hall effect were carried out on a series of well-characterized, covalently modified boron-and nitrogen-doped graphenes. The results obtained demonstrate the validity of this approach. The experimental data show that the introduction of substituents onto aryl groups attached to nitrogen and boron dopants enables the density and mobility of charge carriers on the graphene sheet to be altered in a predictive manner.

The main purpose of this work is to show that covalent functionalization on the heteroatom of defective graphenes is a powerful tool to tune the electronic properties by applying concepts from organic chemistry. In this way, the presence of electron-donor or -acceptor moieties can introduce or remove electrons from the heteroatoms, respectively, and the electronegativity of these heteroatoms can thus be modulated. Since the reactivity of organic nitrogen and boron compounds is well known, it was envisaged that specific reactions from organic chemistry could also be applied for the functionalization of doped graphenes. The hypothesis of the present study is that functionalization of the dopant elements on graphene should be applicable to achieve control of the mobility and density of carriers in the modified graphene.

So, two different doped graphenes were used in this study: a commercial sample of nitrogen-doped graphene $(N(G))$ (http://www.timesnano.com) employed and a borondoped graphene $(B(G))$ was-prepared according to a literature method. ${ }^{6}$ The synthesized $B(G)$ material contained two types of $B$ atoms within the carbon lattice: a component corresponding to $\mathrm{BC}_{3}$ environment $(191.1 \mathrm{eV})$ and other component attributable to $\mathrm{B}$ atoms in $\mathrm{BC}_{2} \mathrm{O} / \mathrm{BCO}_{2}$ coordination $(192.7 \mathrm{eV})^{7,8}$ (see further details in XPS characterization). The vacant atomic $\mathrm{p}_{\mathrm{z}}$ orbital of boron in $\mathrm{BC}_{3} \quad$ component could allow the functionalization of this site with Lewis bases and nucleophiles, ${ }^{9}$ making possible the formation of a Lewis acid-base adduct, being $\mathrm{B}$ atom of $\mathrm{BC}_{3}$ component the only reactive site to be functionalized (see Scheme 1). In this way, preparation of modified $B(G)[f-B(G)$ nanohybrids (1-2)] 


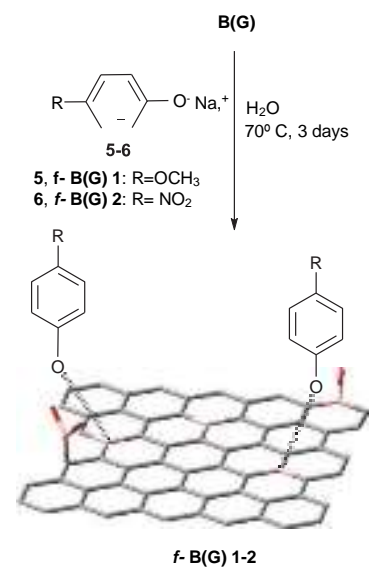

Scheme 1 Preparation of the desired $f-B(G)$ nanohybrids $\mathbf{1 - 2}$.

was carried out by treating at $70{ }^{\circ} \mathrm{C}$ for $3 \mathrm{~d}$ an aqueous suspension of exfoliated $B(G)$ with sodium phenolates (5-6) that had significantly different substituent (Scheme 1). Sodium phenolates were obtained by deprotonation of the corresponding phenol using sodium hydroxide as base. ${ }^{10}$

Preliminary evidence supporting the success of $B$ functionalization in $B(G)$ was obtained by thermogravimetric analysis (TGA) by comparing the relative weight loss for the functionalized $\boldsymbol{f}-\mathrm{B}(\mathbf{G})$ samples 1-2 with that of the starting $B(G)$ (Fig. S1, in $\mathrm{ESI}+$ ). The $\mathrm{B}(\mathrm{G})$ material showed an initial weight loss $(8.3 \%)$ at around $200{ }^{\circ} \mathrm{C}$ due to water desorption and gas evolution from defects present in the $B(G)$ material. The two nanohybrid materials gave new thermal decomposition profiles with weight losses of $15.6 \%$ and $16.7 \%$ for $\mathbf{1}$ and $\mathbf{2}$, respectively. These losses are attributable to of the decomposition of the grafted phenolates anchored to the graphene layer.

Raman spectroscopy provided additional information to support the successful modification of $B(G)$ (Fig.1). As reported in the literature, $B(G)$ presents two characteristic peaks at 1348 $\mathrm{cm}^{-1}$ (to the defect sites or lattice distortion) and $1583 \mathrm{~cm}^{-1}\left(\mathrm{sp}^{2}\right.$ $\mathrm{C}),{ }^{11}$ corresponding to $\mathrm{D}$ and $\mathrm{G}$ bands, respectively. Boron doping introduces a significant number of defects and causes structural and electronic changes in the graphene. These changes are reflected by an increase in the intensity of the $D$ band as compared to graphitic materials. ${ }^{12}$ The density of defects can be quantified to some extent by the intensity ratio between the $D$ and $G$ bands (I / I ). After functionalization,

significant changes in the $I_{D} / I_{G}$ ratio were not observed and this suggests that the reaction occurs at the B atoms. In fact, a careful analysis of the position of the $G$ peak and its shift as a function of the substitution on the $B$ atom was carried out. It has been reported that the wavenumber of the $G$ band is sensitive to charge density on the graphene sheet; ${ }^{13}$ the interaction of electron-withdrawing molecules upshifts the Raman $G$ band, while the opposite effect is observed for electron-donating molecules, which leads to a downshift in the position of the $G$ band. The Raman spectra of $\boldsymbol{f}-\mathbf{B}(\mathbf{G})$ hybrids 1 2 are shown in Fig. 1 along with that of the starting $B(G)$. It was

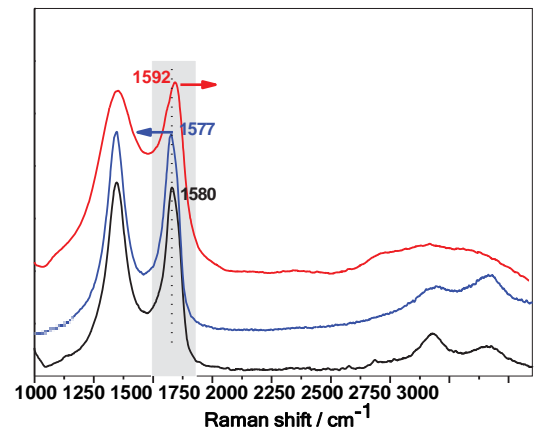

Fig. 1 Raman spectra of samples deposited on $\mathrm{SiO}_{2}$ wafer of $B(G)(-), f-B(G) \mathbf{1}(-)$ and $f-B(G) 2(-)$. The spectra are normalized in the intensity of the $G$ band $\left(\lambda_{\text {exc }}=532 \mathrm{~nm}\right)$.

observed that $\mathrm{G}$ band in nanohybrid $\mathbf{1}$ is downshifted by $\sim 3 \mathrm{~cm}^{-1}$ when compared to the $B(G)$ material, a finding that is consistent with the expected influence of functionalization with an electron-donor group ( $n$-doping). In contrast, the maximum of the $\mathrm{G}$ band for hybrid 2 is upshifted by $\sim 12 \mathrm{~cm}^{-1}$ and this is consistent with the functionalization with a strong electronacceptor substituent (nitrophenolate).

X-ray photoelectron spectroscopy (XPS) confirmed the functionalization of materials $\mathbf{1}$ and $\mathbf{2}$ by providing the elemental composition of the doped graphene surface (Tables $\mathrm{S} 1-\mathrm{S} 2$ in $\mathrm{ESI}+$ for further details). The survey spectrum of $\mathrm{B}(\mathrm{G})$ is presented in Fig. S2 and it displays the presence of $B$ and in addition to C. ${ }^{6}$ Several changes were observed after functionalization: (i) an increase in the $\mathrm{sp}^{3} \mathrm{C}$ component was observed for $f-B(G) \mathbf{1}$ in the high-resoluction $C$ 1s highresolution peak at $285.5 \mathrm{eV},{ }^{14}$ which is attributable to the methoxy substituent, as it reported in previous studies. ${ }^{15}$ In contrast, the spectrum of $\boldsymbol{f}-\mathbf{B}(\mathbf{G}) \mathbf{2}$ showed the appearance of a $\mathrm{N} 1 \mathrm{~s}$ peak $(405.9 \mathrm{eV})$ in agreement with the incorporation of the nitrophenolate substituent. ${ }^{16,17}$

The characterization data discussed above are also in good agreement with the FT-IR spectra. The characteristic IR peaks for the $B(G)$ are shown in Fig. $S 3 ;^{6}$ methoxy derivative $f-B(G) 1$

displays new bands that could be related to vibration of the ether group, i.e., ( $\mathrm{Ar}-\mathrm{O}-\mathrm{C}$ ) at $1226 \mathrm{~cm}^{-1}$ and (C-O-C) around 1029 $\mathrm{cm}^{-1}$. The spectrum of derivative 2 exhibits bands associated to the nitro group at 1581 and $1305 \mathrm{~cm}^{-1}$ which further corroborates the successful incorporation of phenolates into $B(G)$.

Besides B-doped graphene, the study also included the functionalization of $\mathrm{N}$-doped graphene $(\mathrm{N}(\mathrm{G}))$. The commercial starting material $\mathrm{N}(\mathrm{G})$ exhibits three types of $\mathrm{N}$ atoms within the carbon lattice: pyridine-type N (398.2 eV), pyrrole-type N (400.2 $\mathrm{eV}$ ) and quaternary $\mathrm{N}(401.6 \mathrm{eV})$. Nanohybrids 3-4, analogous to 1-2, were prepared in this case, by nucleophilic $\mathrm{N}$-arylation of the $\mathrm{N}$ atoms, being pyrrole-type $\mathrm{N}$ the most reactive to be functionalized, as reported in our previous work ${ }^{18,19}$ (Scheme 2 ). Two different bases were employed in order to study the influence of the level of functionalization: potassium carbonate $\left(\mathrm{K}_{2} \mathrm{CO}_{3}\right)$ for lower contents of electroactive units and cesium carbonate $\left(\mathrm{CsCO}_{3}\right)$ with the presence of copper bromide $(\mathrm{CuBr})$ for the incorporation of higher loadings of the organic addend 


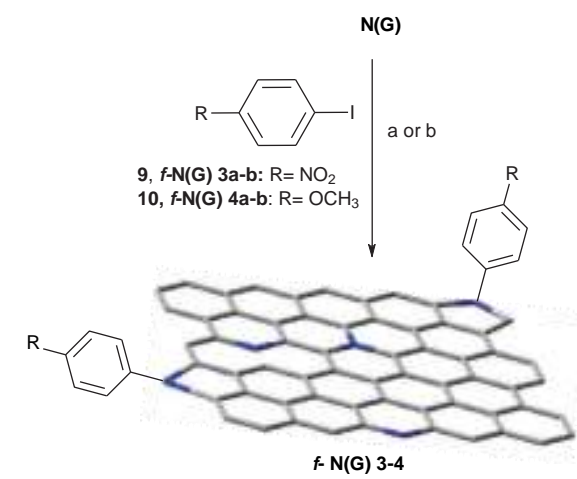

Scheme 2 Synthetic route for target $f$-N(G) 3-4. Reagents and conditions: (a) NMP, $\mathrm{K}_{2} \mathrm{CO}_{3}$, $120^{\circ} \mathrm{C}, 1$ day; (b) NMP, $\mathrm{CsCO}_{3}, \mathrm{CuBr}, 150^{\circ} \mathrm{C}, 4$ days.

\section{(Scheme 2).}

TGA data for nitrogen-functionalized samples 3-4 are provided in Fig. S4. Covalent functionalization with the corresponding aryl derivatives (9-10) led to a significant increase in the weight loss to 30.7 and $48 \%$ for $\mathbf{3 a}$ and $\mathbf{3 b}$, respectively, due to the nitrophenyl units (Fig. S4a). In the case of methoxyphenyl, the weight losses corresponding to the attached organic moieties were 21.3 and $39.1 \%$ for $\mathbf{4 a}$ and $\mathbf{4 b}$, respectively (Fig. S4b). These data confirmed the successful incorporation of the organic moieties onto $N(G)$ with different levels of functionalization on the surface surface.

The Raman spectra for $\mathbf{f}-\mathbf{N}(\mathbf{G})$ hybrids 3-4 are shown in Fig. 2 along with that of the $N(G)$ precursor. The characteristics $D$ and $G$ bands can be clearly observed. As in the case of the aforementioned $B(G)$, an upshift in the $G$-band consistent with

the functionalization of $N(G)$ with an electron-acceptor (nitrophenyl) was observed for $\boldsymbol{f}$-N(G) 3a-b (Fig. 2a), whereas a downshift of the position of the $G$ band was evident for $f-N(G)$ $\mathbf{4 a - b}$, which bears electron-donating methoxyphenyl units (Fig.

$2 b)$. It is interesting to note that the shift in the $G$ band correlates well with the degree of functionalization, with larger shifts observed for more functionalized samples $\mathbf{3 b}$ and $\mathbf{4 b}$. It will be commented later that these samples also exhibited the largest differences in charge mobility and Hall voltage, ${ }^{20,21}$ when compared to the samples with a lower degree of functionalization (3a and 4a) (see Table S3 in ESIt and Table 1).

The XPS data also supports the successful modification of $N(G)$, as demonstrated by the appearance of new elements arising from the functionalization (see Table S4 in ESIt).

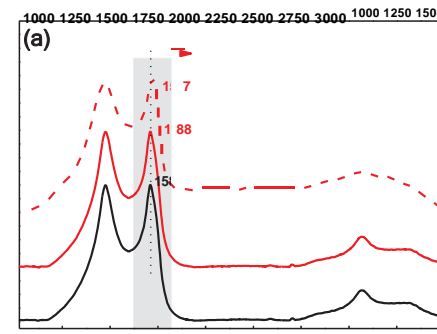

Raman shift / $\mathrm{cm}$

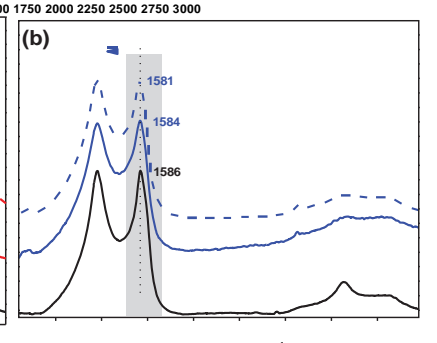

Raman shift $/ \mathrm{cm}^{-1}$
Fig. 2 Raman spectra of samples deposited on $\mathrm{SiO}_{2}$ wafer of (a) $\mathrm{N}(\mathrm{G})(-), f-\mathrm{N}(\mathrm{G}) \mathbf{3 a}(-)$ and $f-\mathrm{N}(\mathrm{G})$ 3b (...) and (b) $\mathrm{N}(\mathrm{G})(-), f-\mathrm{N}(\mathrm{G})$ 4a $(-)$ and $f-\mathrm{N}(\mathrm{G}) \mathbf{4 b}(\ldots)$. Dashed lines correspond to materials with a higher density of organic moieties. The spectra are normalized by the intensity of the G-band $\left(\lambda_{\text {exc }}=532 \mathrm{~nm}\right.$ ).
$\mathbf{N}(\mathbf{G}) \mathbf{3 b}$ is shown in Fig. S5 (upper panel) as in the case of nitro derivative $f-B(G) 2$. Similarly, the high resolution C1s peak of $f$ $\mathbf{N}(\mathbf{G}) \mathbf{4 b}$ indicates a new $\mathrm{sp}^{3} \mathrm{C}$ component at $285.2 \mathrm{eV},{ }^{14}$ which is due to the presence of the methoxy group in this material (Fig. S5, bottom panel). All of these features are consistent with the TGA and Raman data and they support covalent functionalization in the $\mathrm{N}$-doped material.

The successful functionalization of the $\mathrm{N}$ atoms in $\mathrm{N}(\mathrm{G})$ was further confirmed by IR spectroscopy (Fig. S6). The IR spectra contain, in the case of the $f-\mathbf{N}(\mathbf{G})$ materials (3-4), the expected bands corresponding to the methoxy and nitro groups. Thus, hybrid 3 presented two peaks at 1517 and $1341 \mathrm{~cm}^{-1}$, i.e., slightly shifted when compared to the phenolic precursor, due to the existence of nitro group on $\mathrm{N}(\mathrm{G})$. In the case of derivative 4 , the $\mathrm{Ar}-\mathrm{O}-\mathrm{C}$ band due to the ether group $\left(1214 \mathrm{~cm}^{-1}\right)$ was also observed (Fig. S6b).

Finally, additional structural data for the functionalized doped graphene materials (1-4) were gathered by AFM investigations (Figs. S7-S10 in ESI + ). The images obtained for the starting material $B(G)$ are shown in Fig. S7. The presence of flakes of various dimensions and well-defined edges, with an average height in the range 3-3.5 $\mathrm{nm}$, was observed along with thinner sheets with an average height of $c a .1 .2 \mathrm{~nm}$. After functionalization the average thickness of $f-\mathbf{B}(\mathbf{G})$ 1-2 was greater than that of the starting material and different height levels were observed along with the presence of bright zones ascribed to the organic aggregates (Fig. S8), which could suggest the presence of the phenolate attached to B-doped graphene. Similar results were obtained for $\mathrm{N}$-doped graphene materials (Figs. S9-S10). X-Ray Diffractions (XRD) analysis were also perfomed showing changes in the material after functionalization (Fig. S11 in ESI†).

With the aim of providing experimental support to the novel concept on graphene chemistry proposed here, the intensity of Hall effect was measured for the series of samples under study $\mathrm{B}(\mathrm{G}), \mathrm{N}(\mathrm{G}), \boldsymbol{f}$-B(G) $\mathbf{1 - 2}$ and $\boldsymbol{f}-\mathbf{N}(\mathrm{G}) \mathbf{3 - 4}$ (see Figs. S12-S14 for further details). It was observed that the Hall voltage and the electrical resistance of films changed as a function of the nature of the dopant element, the nature of substituents on the aromatic ring and the degree of functionalization. The results are summarized in Table 1 and Table S5 in ESIt. As a general observation, electrical resistance increased upon functionalization of the dopant element in all cases. This finding can be understood on considering that covalent functionalization with strong electron-donating or-withdrawing units should be considered in a specific way, i.e., as defects on ideal graphene sheets.

From the data in Table 1 it can be seen that the most salient results are the opposite effects that the covalently attached electron donor or acceptor units have depending on the dopant element, i.e., boron or nitrogen. In the case of $\mathrm{N}$-doped graphene $(N(G))$, which corresponds to an $n$-type
semiconductor, the nitro group increases the density of the

carriers, whereas methoxy groups have the opposite effect. The influence of the nitro and methoxy groups becomes more marked as the level of functionalization increases (a: low degree of functionalization and $b$ : high degree of functionalization). 
Table 1. Resistance, Hall mobility and surface density of charge carriers for the series of functionalized graphene materials under study.

\begin{tabular}{|c|c|c|c|}
\hline Sample & $\begin{array}{l}\text { Resistance } \\
\text { [K } \Omega / \text { square] }\end{array}$ & $\begin{array}{l}\text { Hall mobility of the } \\
\text { charge carriers } \\
\mathbf{v}\left[\mathrm{cm}^{2} \cdot \mathrm{v}^{-1} \cdot \mathrm{s}^{-1}\right]\end{array}$ & $\begin{array}{l}\text { Surface density } \\
\text { of } \\
\text { carriers }\left[\mathrm{cm}^{-2}\right]\end{array}$ \\
\hline$B(G)$ & 174 & 0.05983 & $6.00 E+14$ \\
\hline$f-B(G) 1$ & 181 & 0.02935 & $1.18 \mathrm{E}+15$ \\
\hline$f-B(G) 2$ & 384 & 0.41862 & $3.88 \mathrm{E}+14$ \\
\hline$N(G)$ & 0.56 & 4.38871 & $2.54 \mathrm{E}+15$ \\
\hline$f-\mathrm{N}(\mathrm{G}) 3 \mathrm{a}$ & 2.78 & 0.71690 & $3.14 \mathrm{E}+15$ \\
\hline$f-N(G) 3 b$ & 11.02 & 0.13127 & $4.32 \mathrm{E}+15$ \\
\hline$f-\mathrm{N}(\mathrm{G}) 4 \mathrm{a}$ & 4.16 & 0.87181 & $1.72 \mathrm{E}+15$ \\
\hline$f-\mathrm{N}(\mathrm{G}) 4 \mathrm{~b}$ & 9.75 & 0.62371 & $1.03 E+15$ \\
\hline
\end{tabular}

Therefore, the highest surface density of carriers is achieved with the highest level of nitrophenyl groups on the nitrogen atoms $[\boldsymbol{f}-\mathbf{N}(\mathbf{G}) \mathbf{3 b}]$. As far as mobility of the charge carriers is concerned, and as a direct consequence of the increase in the electrical resistance, it was observed that carrier mobility decreased upon covalent functionalization of the nitrogen atoms. Once again, the extent of this decrease was correlated to the level of $\mathrm{N}$-atoms functionalization.

In the case of boron-doped graphene $(B(G))$, which was reported ted to be a $p$-type semiconductor based on the sense of the Hall effect, opposite effects were observed to those describe above for $N(G)$. Thus, for this material the surface density of charge carriers increased for 4-methoxyphenylsubstitution of boron $(\boldsymbol{f}-\mathbf{B}(\mathbf{G}) \mathbf{1})$, while carrier density decreases when 4-nitrophenyl groups were bonded to the boron atoms ( $f$ B(G) 2). The mobility of the charge carriers decreased upon functionalization and this finding is also consistent with the observation of an increase in the electrical resistance mentioned above. Overall, the data highlight the possibilities offered by organic synthesis for the modification of the electronic properties of doped graphenes. This approach can be considered as effectively expanding the number of available dopant elements by functionalization of the commonly used nitrogen and boron dopants.

In conclusion, unprecedented B-functionalization of Bdoped graphene is reported. It has been demonstrated that the electronic properties of doped graphenes can be effectively modulated by covalent functionalization of $\mathrm{N}$ - and $\mathrm{B}$-doped graphene. The density of defects is related to the degree of functionalization. As a general observation, functionalization of doped graphenes leads to an increase in the electrical resistance of these materials and a change in the Hall effect. For $n$-type graphenes such as $\mathrm{N}(\mathrm{G})$, electron-acceptors substituents increase the surface density of charge carriers, whereas the presence of electron donors decrease this value. The opposite behaviour was observed for the $p$-type graphene $\mathrm{B}(\mathrm{G})$. Overall, the results presented here open new avenues for the rational control of the electronic properties of graphenes and doped graphenes by organic synthesis on applying well-established concepts about the influence of electron-donor and -acceptor groups on aromatic rings. Further work on functionalized Satom doped graphene hybrids is underway in our laboratories.
The authors appreciate support from the Ministerio de Economía y Competitividad (MINECO) of Spain (projects CTQ2015-69153-CO2-1, CTQ2016-79189-R and MAT201569669-P) and the Junta de Comunidades de Castilla-La Mancha (project SBPLY/17/180501/000254). L. M. A. thanks MINECO (CTQ2016-79189-R) for a doctoral FPI grant.

\section{Conflicts of interest}

There are no conflicts to declare.

\section{References}

1 X. Wang, G. Sun, P. Routh, D.-H. Kim, W. Huang and P. Chen, Chem. Soc. Rev., 2014, 43, 7067.

2 C. Lavorato, A. Primo, R. Molinari and H. García, Chem. Eur. J., 2014, 20, 187.

3 M. Latorre-Sánchez, A. Primo and H. García, Angew. Chem Int. Ed., 2013, 52, 11813.

4 J. Duan, S. Chen, M. Jaroniec and S.Z. Qiao, ACS Catal., 2015, 5, 5207.

5 L. K. Putri, W.-J. Ong, W.S. Chang and S.-P. Chai, Appl. Surf. Sci., 2015, 358, 2.

6 L. Niu, Z. Li, W. Hong, J. Sun, Z. Wang, L. Ma, J. Wang and S. Yang, Electrochim. Acta, 2013, 108, 666.

7 M. Sahoo, K.P. Sreena, B.P. Vinayan and S. Ramaprabhu, Mater. Res. Bull., 2015, 61, 383.

8 T. V. Khai, H.G. Na, D.S. Kwak, Y.J. Kwon, H. Ham, K.B. Shim and H.W. Kim, Chem. Eng. J., 2012, 211-212, 369.

9 S. Osumi, S. Saito, C. Dou, K. Matsuo, K. Kume, H. Yoshikawa, K. Awaga and S. Yamaguchi, Chem. Sci., 2016, 7, 219.

10 Q. Xu, X. Jiang, W. Zhu, C. Chen, G. Hu and Q. Li, Arab. J. Chem., 2016, 9, 721.

11 M. A. Pimenta, G. Dresselhaus, M.S. Dresselhaus, L.G. Cancado, A. Jorio and R. Saito, Phys. Chem. Chem. Phys., 2007, 9, 1276.

12 L. S. Panchakarla, K.S. Subrahmanyam, S.K. Saha, A. Govindaraj, H.R. Krishnamurthy, U.V. Waghmare and C.N.R. Rao, Adv. Mater., 2009, 21, 4726.

13 R. Voggu, C.S. Rout, A.D. Franklin, T.S. Fisher and C.N.R. Rao, J. Phys. Chem. C, 2008, 112, 13053.

14 M. Biswal, X. Zhang, D. Schilter, T. K. Lee, D.Y. Hwang, M. Saxena, S. H. Lee, S. Chen, S.K. Kwak, C. W. Bielawski, W. S. Bacsa and R. S. Ruoff, J. Am. Chem. Soc., 2017, 139, 4202.

15 M. Vizuete, M. J. Gómez-Escalonilla, J. L. G. Fierro, K. Okubo, S. Fukuzumi, M. Yudasaka, S. lijima, J.-F. Nierengarten and F. Langa, Chem. Sci., 2014, 5, 2072.

16 P. Allongue, M. Delamar, B. Desbat, O. Fagebaume, R. Hitmi, J. Pinson and J. M. Saveant, J. Am. Chem. Soc., 1997, 119, 201.

17 M. Barrejón, M. J. Gómez-Escalonilla, J. L. G. Fierro, P. Prieto, J. R. Carrillo, A. M. Rodríguez, G. Abellán, M. C. LópezEscalante, M. Gabás, T. López-Navarrete and F. Langa, Phys. Chem. Chem. Phys., 2016, 18, 29582.

18 M. Barrejón, A. Primo, M. J. Gómez-Escalonilla, J. L. G. Fierro, H. García and F. Langa, Chem. Commun., 2015, 51, 16916.

19 M. Barrejón, L. M. Arellano, H. B. Gobeze, M. J. GómezEscalonilla, J. L. G. Fierro, F. D'Souza and F. Langa, Chem. Sci., 2018, 9, 8221.

20 Y. Su, J. Du, D. Sun, C. Liu and H. Cheng, Nano Res., 2013, 6, 842.

21 C.-Y. Su, Y. Xu, W. Zhang, J. Zhao, X. Tang, C.-H. Tsai and L.-J. Li, Chem. Mater., 2009, 21, 5674.

4 | J. Name., 2012, 00, 1-3 


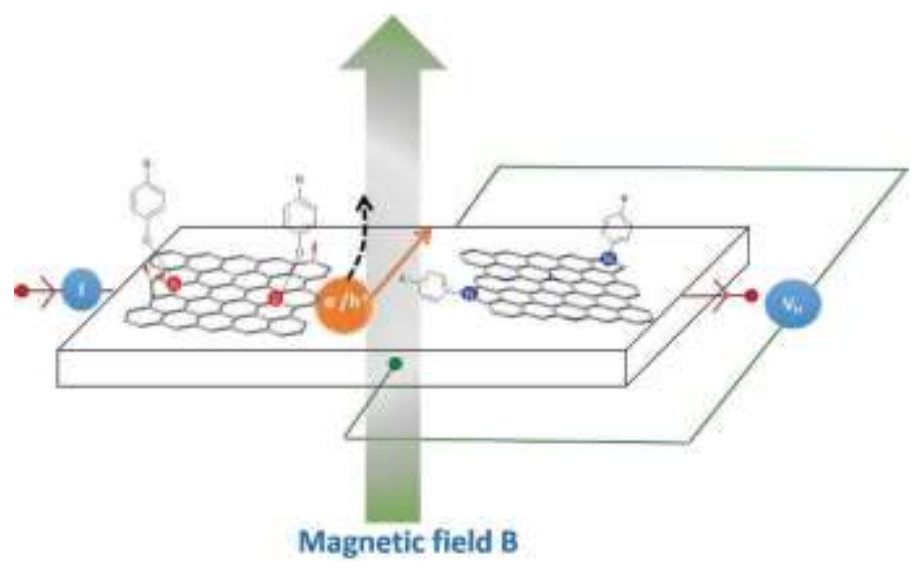

We describe by the first time the covalent B-functionalization of B-Graphene. Besides, Hall effect can be can be modulated by the nature of the organic addend 



\section{Electronic Supporting Information}

\section{Modulating Charge Carrier Density and Mobility in Doped}

\section{Graphene by Covalent Functionalization}

Luis Miguel Arellano, ${ }^{\dagger}{ }^{\dagger}$ Sun Yue, ${ }^{\ddagger}$ Pedro Atienzar, ${ }^{+,+}$María J. Gómez-Escalonilla, ${ }^{\dagger}$ Francisco

J. Ortega-Higueruelo, ${ }^{\dagger}$ José Luis G. Fierro, ${ }^{\S}$ Hermenegildo García ${ }^{*}+\grave{t}$ and Fernando Langa* ${ }^{\dagger}$

Universidad de Castilla-La Mancha, Instituto de Nanociencia, Nanotecnología y Materiales

Moleculares (INAMOL), 45071-Toledo, Spain.E-mail: Fernando.Langa@uclm.es

Instituto Universitario de Tecnología Química, CSIC-UPV, Universitat Politécnica de

Valencia, 46022, Valencia, Spain. E-mail: hgarcia@qim.upv.es

Instituto de Catálisis y Petroleoquímica, CSIC, Cantoblanco, 28049, Madrid.

E-mail:jlgfierro@icp.csic.es

*Corresponding author: Fernando.Langa@uclm.es, hgarcia@qim.upv.es 


\section{Materials and Instrumentation}

Nitrogen-doped graphene $[\mathrm{N}(\mathrm{G})$, grade TNNRGO] with a nitrogen content of 5 10\% wt was supplied by Chengdu Organic Chemicals Co. Ltd., Chinese Academy of Sciences (Chengdu, China) (www.timesnano.com). Boron-doped graphene $(\mathrm{B}(\mathrm{G}))$ was synthesized according to literature procedure. ${ }^{1}$

Organic solvents and reagents used in this work were purchased from commercial suppliers and used as received, unless otherwise stated.

Sample sonication was carried out using an Elmasonic P 300 h sonicator bath $(37 \mathrm{kHz})$.

FTIR spectra were recorded on a Fourier Transform IR spectrophotometer (Avatar 370) in the range of $4000-400 \mathrm{~cm}^{-1}$, with a resolution of $1 \mathrm{~cm}^{-1}$, and in pellets of dispersed samples of the corresponding materials in dried $\mathrm{KBr}$.

Thermogravimetric analyses (TGA) were performed using a TGA/DSC Linea Excellent instrument by Mettler-Toledo, collected under a flow of nitrogen $\left(90 \mathrm{~mL} \cdot \mathrm{min}^{-1}\right)$. The sample ( $0.5 \mathrm{mg}$ ) was introduced into a platinum crucible and equilibrated at $40{ }^{\circ} \mathrm{C}$ followed by a 10 ${ }^{\circ} \mathrm{C} / \mathrm{min}$ ramp between $40{ }^{\circ} \mathrm{C}$ and $1000{ }^{\circ} \mathrm{C}$. The weight changes were recorded as a function of temperature.

X-ray photoelectron spectra (XPS): XPSK-ALPHA, Thermo Scientific was used to analyse the samples surface. All spectra were collected using Al-K radiation (1486.6 eV), monochromatized by a twin crystal monochromator, to yield a focused X-ray spot (elliptical in shape with a major axis length of $400 \mu \mathrm{m}$ ) at $3 \mathrm{~mA} \times 12 \mathrm{kV}$. The alpha hemispherical analyser was operated in the constant energy mode with survey scan pass energies of $200 \mathrm{eV}$ to measure the whole energy band and $50 \mathrm{eV}$ in a narrow scan to measure specific elements selectivity. XPS data were analysed with Avantage software. A smart background function was used to approximate the experimental backgrounds and surface elemental composition were calculated from background-subtracted peak areas. Charge compensation was achieved with the flood gun system, which provides low energy electrons and low energy argon ions from a single source. 
Raman spectra were obtained on a Renishaw inVia Raman instrument coupled with a Leica microscope at room temperature with a $532 \mathrm{~nm}$ exciting laser. The samples were deposited on $\mathrm{SiO}_{2}$ wafers.

AFM images were acquired in tapping mode using a Multimode V8.10 system (Veeco Instruments Inc., Santa Barbara, USA) with a NanoScope V controller (Digital Instruments, Santa Barbara, USA) operating at room temperature in ambient air conditions. The cantilevers (RTESP from Bruke Probes) were silicon cantilevers with a resonance frequency of $300 \mathrm{kHz}$ and a nominal force constant of $40 \mathrm{Nm}^{-1}$ The functionalized samples $\left(0.2 \mathrm{mg} \mathrm{m}^{-1}\right)$ were prepared by sonication (frequency: $37 \mathrm{kHz}$; power $380 \mathrm{~W}$ ) in ethanol for $1500 \mathrm{~min}$, followed by ultracentrifugation at $13000 \mathrm{rpm}$ for $5 \mathrm{~min}$ to remove the heavier material. Samples were prepared by spin coating on $\mathrm{SiO}_{2}$ surfaces previously functionalized with (3aminopropyl)triethoxysilane.

X-ray diffraction patterns were obtained in a Philips X'Pert diffractometer using the copper radiation $(\mathrm{Cu}-\mathrm{K} \alpha=1.54178 \AA)$. 


\section{Exfoliation procedure}

For $\mathbf{B}(\mathbf{G})$ material: $\mathrm{B}(\mathrm{G})(1 \mathrm{mg})$ was dispersed in distilled water $(1 \mathrm{~mL})$ at room temperature using an Elmasonic P $300 \mathrm{H}$ sonicator bath $(37 \mathrm{kHz})$. After $120 \mathrm{~min}$ of sonication, the resulting dispersion was centrifuged for $10 \mathrm{~min}$ at $500 \mathrm{rpm}$ and the supernatant was separated from the product on the bottom of the vessel by pipetting the liquid phase.

For $\mathbf{N}(\mathbf{G})$ material: $\mathrm{N}(\mathrm{G})(1 \mathrm{mg})$ were dispersed in $N$-methyl 1-pyrrolidone (NMP) (3 mL) at room temperature using an Elmasonic $\mathrm{P} 300 \mathrm{H}$ sonicator bath $(37 \mathrm{kHz})$. After $30 \mathrm{~min}$ of sonication, the resulting dispersion was centrifuged for $10 \mathrm{~min}$ at $500 \mathrm{rpm}$ and the supernatant was separated from the product on the bottom of the vessel by pipetting the liquid phase.

In both cases, the concentration in the resulting dispersions was determined by recording the absorbance at $660 \mathrm{~nm}$ and transforming this into the concentration using the Lambert-Beer law $\mathrm{A} / \mathrm{l}=\alpha \mathrm{c}$ with a $\alpha=2.460 \mathrm{mLmg}^{-1} \mathrm{~m}^{-1}$ 


\section{Synthetic procedure for phenolates $5-6:^{2}$}

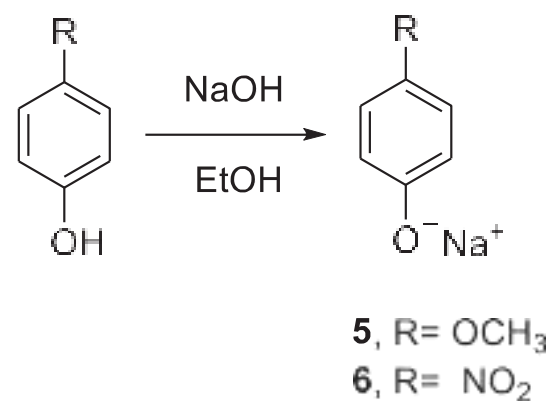

Sodium hydroxide $(16.7 \mathrm{mmol}, 1 \mathrm{eq})$ in anhydrous ethanol $(5 \mathrm{~mL})$ was added dropwise to a solution of the corresponding substituted phenol derivative (14.4 mmol, $1.1 \mathrm{eq})$ in ethanol (4 $\mathrm{mL}$ ). The reaction solution was stirred at room temperature for $30 \mathrm{~min}$. The precipitate was filtered off and washed with cold diethyl ether to remove the starting material. The solid residue was dried under vacuum to afford the corresponding sodium methoxyphenolate $\mathbf{5}$ and sodium nitrophenolathe 6 in yields of $82 \%$ and $98 \%$, respectively.

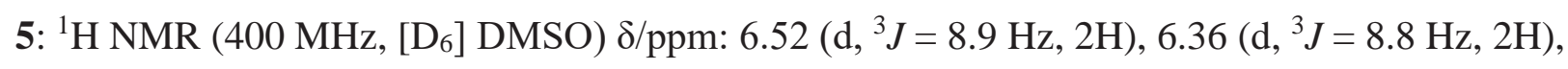
$3.57\left(\mathrm{~s}, 3 \mathrm{H}, \mathrm{CH}_{3}\right)$.

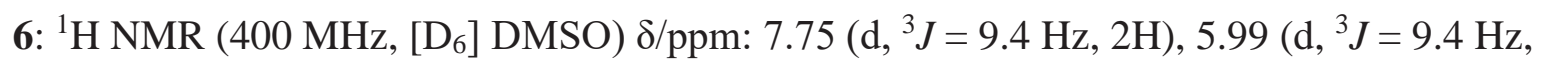
$2 \mathrm{H})$.

\section{General synthetic procedure of $f$-B (G) materials 1 and 2:}

To a suspension of exfoliated B-doped graphene $(40 \mathrm{mg})$ in water $(60 \mathrm{~mL})$ was added the corresponding sodium phenolate [(5: $2433 \mathrm{mg}, 16.6 \mathrm{mmol})$ or $(6: 2766 \mathrm{mg}, 16.6 \mathrm{mmol})]$ and the suspension sonicated for $15 \mathrm{~min}$. The reaction mixture was stirred at $70{ }^{\circ} \mathrm{C}$ for $3 \mathrm{~d}$. The mixture was allowed to cool down to room temperature, filtered through a PTFE membrane (Millipore, $0.1 \mu \mathrm{m}$ pore) and the black solid was collected and washed consecutively with water, methanol and dichloromethane until the filtrate becomes colourless. The black solid was dried overnight in a vacuum oven at $55^{\circ} \mathrm{C}$ to obtain $f-\mathbf{B}(\mathbf{G}) \mathbf{1}$ and $\mathbf{2}$. 


\section{General synthetic procedure of $f-\mathrm{N}(\mathrm{G})$ materials 3 and 4:}

Synthesis of $f-\mathrm{N}(\mathbf{G})$ 3-4a (low degree of functionalization): A suspension of exfoliated $\mathrm{N}(\mathrm{G})$ (15 mg) in NMP (50 mL) was reacted with 9 (1560 mg, $6.2 \mathrm{mmol})$ or $\mathbf{1 0}(1460 \mathrm{~g}, 6.2 \mathrm{mmol})$ and $\mathrm{K}_{2} \mathrm{CO}_{3}$ as base $\left(345 \mathrm{mg}, 2.5 \mathrm{mmol}\right.$ ). The reaction mixture was stirred at $120{ }^{\circ} \mathrm{C}$ for $24 \mathrm{~h}$. After cooling to room temperature, the suspension was filtered through a PTFE membrane (Millipore, $0.1 \mu \mathrm{m}$ pore) and the black solid was collected and washed consecutively with water, methanol and dichloromethane, until the filtrate become colourless. Black solid was dried overnight in a vacuum oven at $55^{\circ} \mathrm{C}$ to obtain $f-\mathbf{N}(\mathbf{G}) \mathbf{3 a}$ and $4 \mathbf{a}$.

Synthesis of $f-\mathbf{N}(\mathbf{G})$ 3-4b (high degree of functionalization): A suspension of exfoliated $\mathrm{N}(\mathrm{G})$ (25 mg) in NMP (50 mL) was reacted with $1(500 \mathrm{mg}, 2 \mathrm{mmol})$ or $2(500 \mathrm{mg}, 2.1 \mathrm{mmol})$, $\mathrm{CsCO}_{3}(416.27 \mathrm{mg}, 3.0 \mathrm{mmol})$ and $\mathrm{CuBr}(58 \mathrm{mg}, 0.4 \mathrm{mmol})$. The reaction mixture was stirred at $150{ }^{\circ} \mathrm{C}$ for $4 \mathrm{~d}$. After cooling to room temperature, the suspension was filtered through a PTFE membrane (Millipore, $0.1 \mu \mathrm{m}$ pore) and the black solid was collected and washed repeatedly with water, methanol and dichloromethane, until the filtrate become colourless. ThebBlack solid was dried overnight in a vacuum oven at $55^{\circ} \mathrm{C}$ to obtain $f-\mathbf{N}(\mathbf{G}) \mathbf{3 b}$ and $\mathbf{4 b}$. 

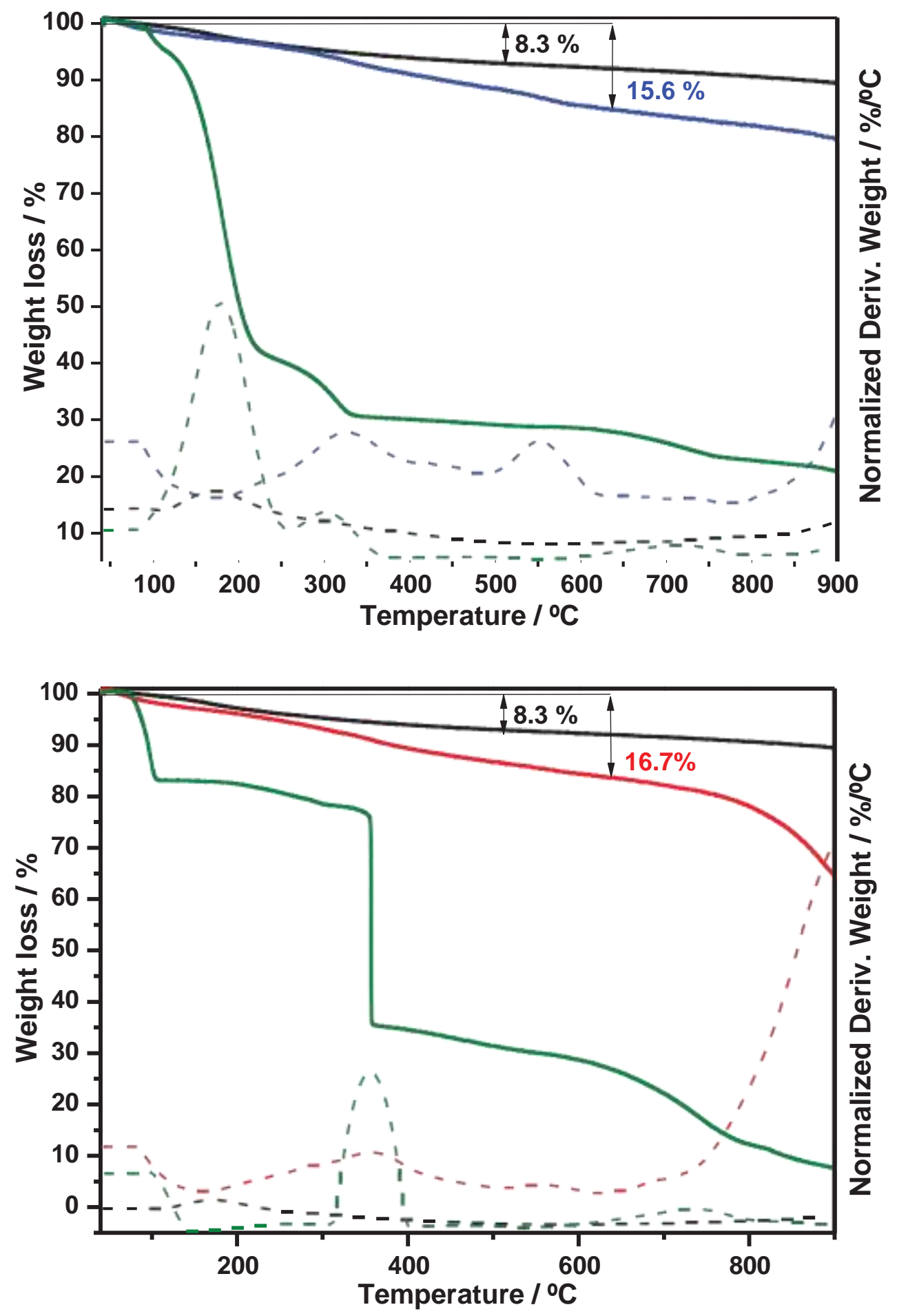

Figure S1. TGA profiles under inert conditions with first derivative of (upper panel) B(G) (-) and $\boldsymbol{f}-\mathbf{B}(\mathbf{G}) \mathbf{1}(-)$ and (bottom panel) $\mathbf{B}(\mathbf{G})(-)$ and $\boldsymbol{f}-\mathbf{B}(\mathbf{G}) \mathbf{2}(-)$, compared with sodium phenolate precursors (-). 


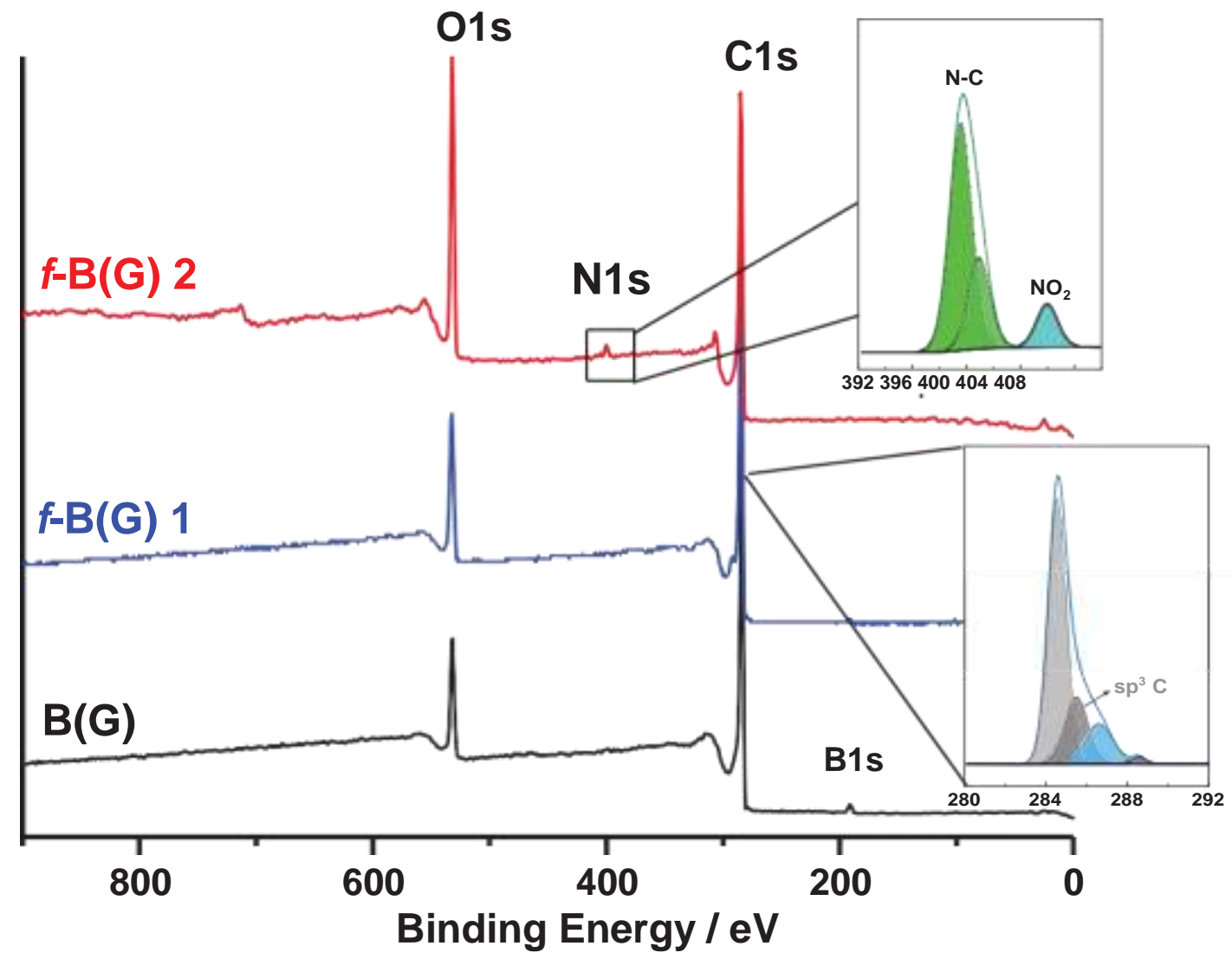

Fig. S2 XPS spectra of $\mathrm{B}(\mathrm{G})(-), \boldsymbol{f}-\mathbf{B}(\mathbf{G}) \mathbf{1}(-)$ and $\boldsymbol{f}$-B(G) 2 (-). The insets correspond to the high-resolution $\mathrm{C} 1 \mathrm{~s}$ and the N1s peaks of $\boldsymbol{f}-\mathrm{B}(\mathbf{G}) \mathbf{1}$ and $\boldsymbol{f}-\mathbf{B}(\mathbf{G}) \mathbf{2}$, respectively. 

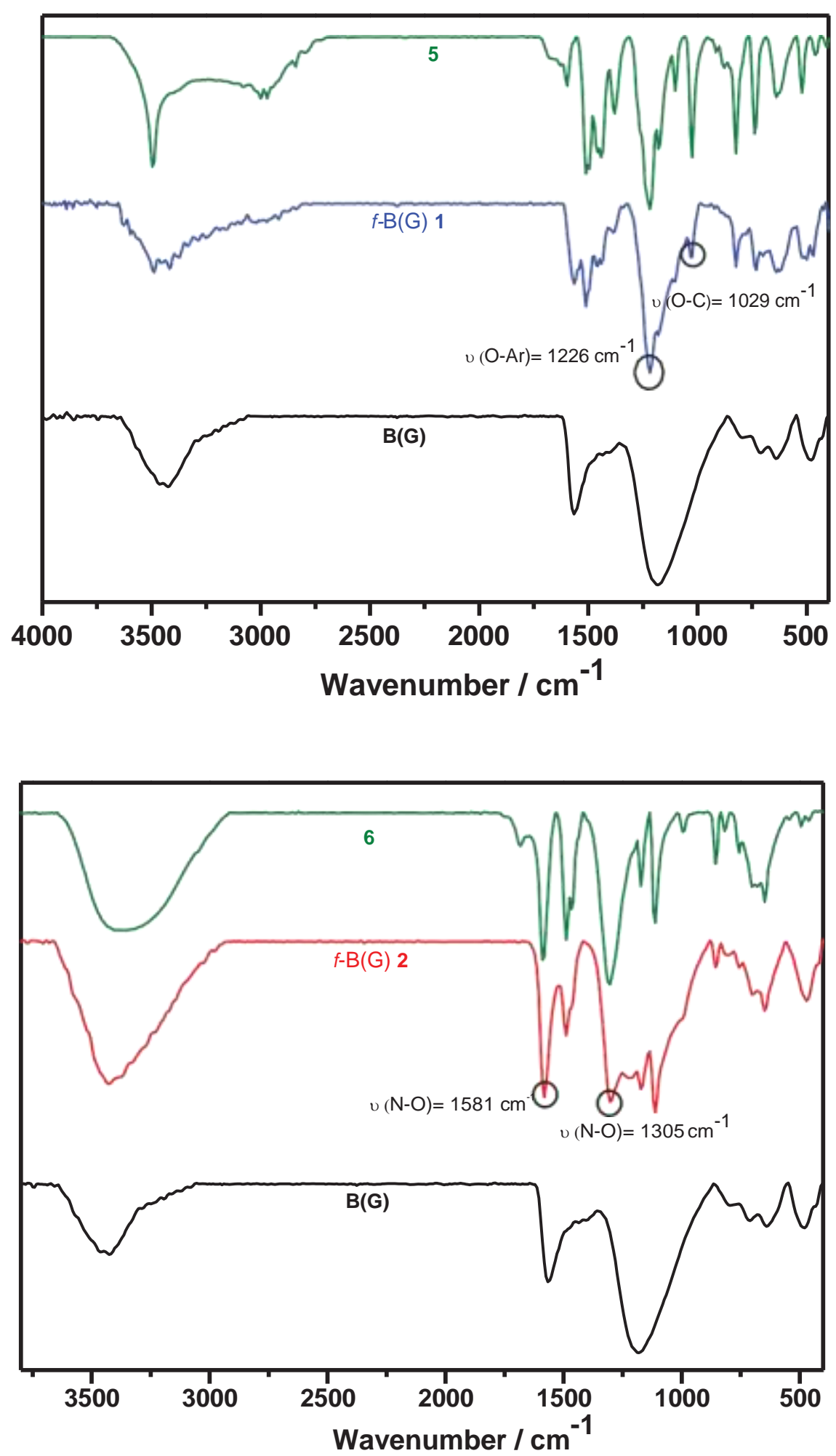

Figure S3. FT-IR spectra of (upper panel) $\mathrm{B}(\mathrm{G})$ compared to final hybrid $\boldsymbol{f}-\mathbf{B}(\mathbf{G}) \mathbf{1}$ and the corresponding phenolate $\mathbf{5}$ and (bottom panel) $\mathbf{B}(\mathbf{G})$ compared to final hybrid $\boldsymbol{f}-\mathbf{B}(\mathbf{G}) \mathbf{2}$ and the corresponding phenolate $\mathbf{6}$. 

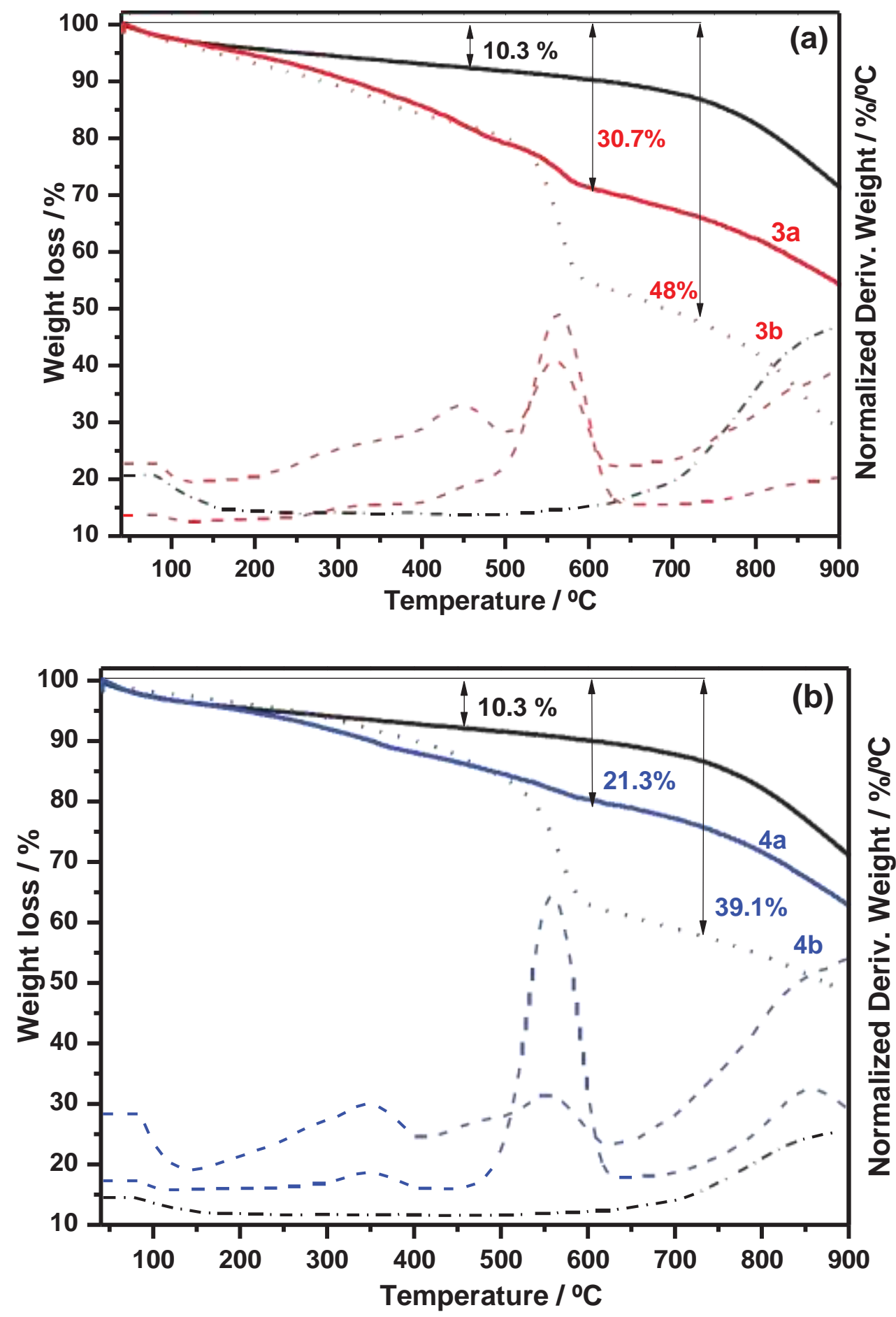

Figure S4. TGA profiles under a nitrogen atmosphere of (a) $\mathrm{N}(\mathrm{G})(-)$ and $\boldsymbol{f}$-N(G) 3a-b materials (-) and (b) $\mathbf{N}(\mathbf{G})(-)$ and $\boldsymbol{f}-\mathbf{N}(\mathbf{G})$ 4a-b (-). Note that dotted lines correspond to more functionalized materials. 

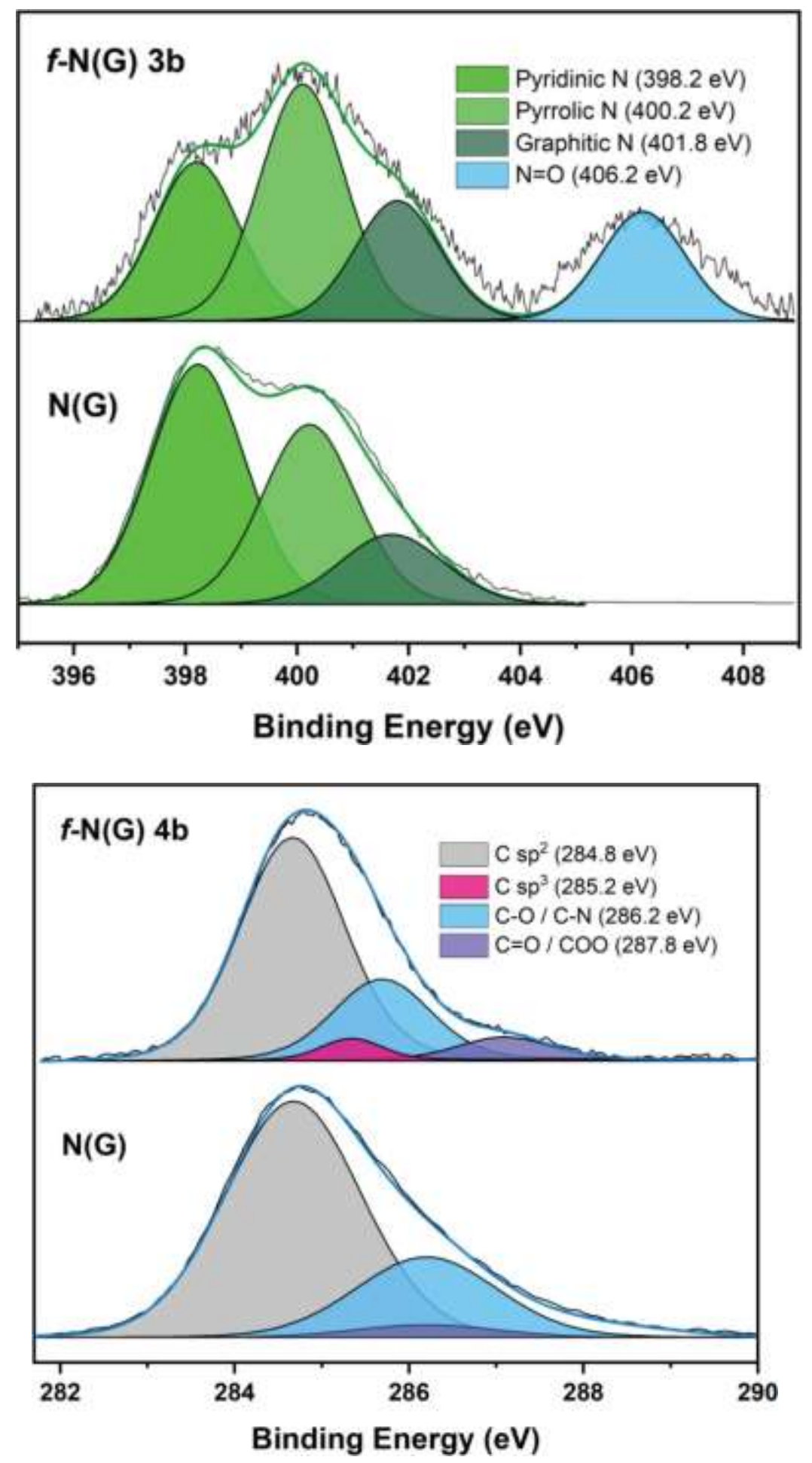

Fig. S5 (upper panel) XPS N1s core level spectra of $N(G)$ compared to that of $\boldsymbol{f}-\mathbf{N}(\mathbf{G}) \mathbf{3 b}$ and their relative fits, showing the nitro component at $406.2 \mathrm{eV}$ (blue curve); (bottom panel) XPS C1s core level spectra of $\mathrm{N}(\mathrm{G})$ compared to that $f-\mathrm{N}(\mathbf{G}) \mathbf{4 b}$ and their relative fits, showing the $\mathrm{sp}^{3} \mathrm{C}$ component at $285.2 \mathrm{eV}$ (magenta curve). The atomic percentages (at.\%) of each component are shown in Table S4 in ESI. 

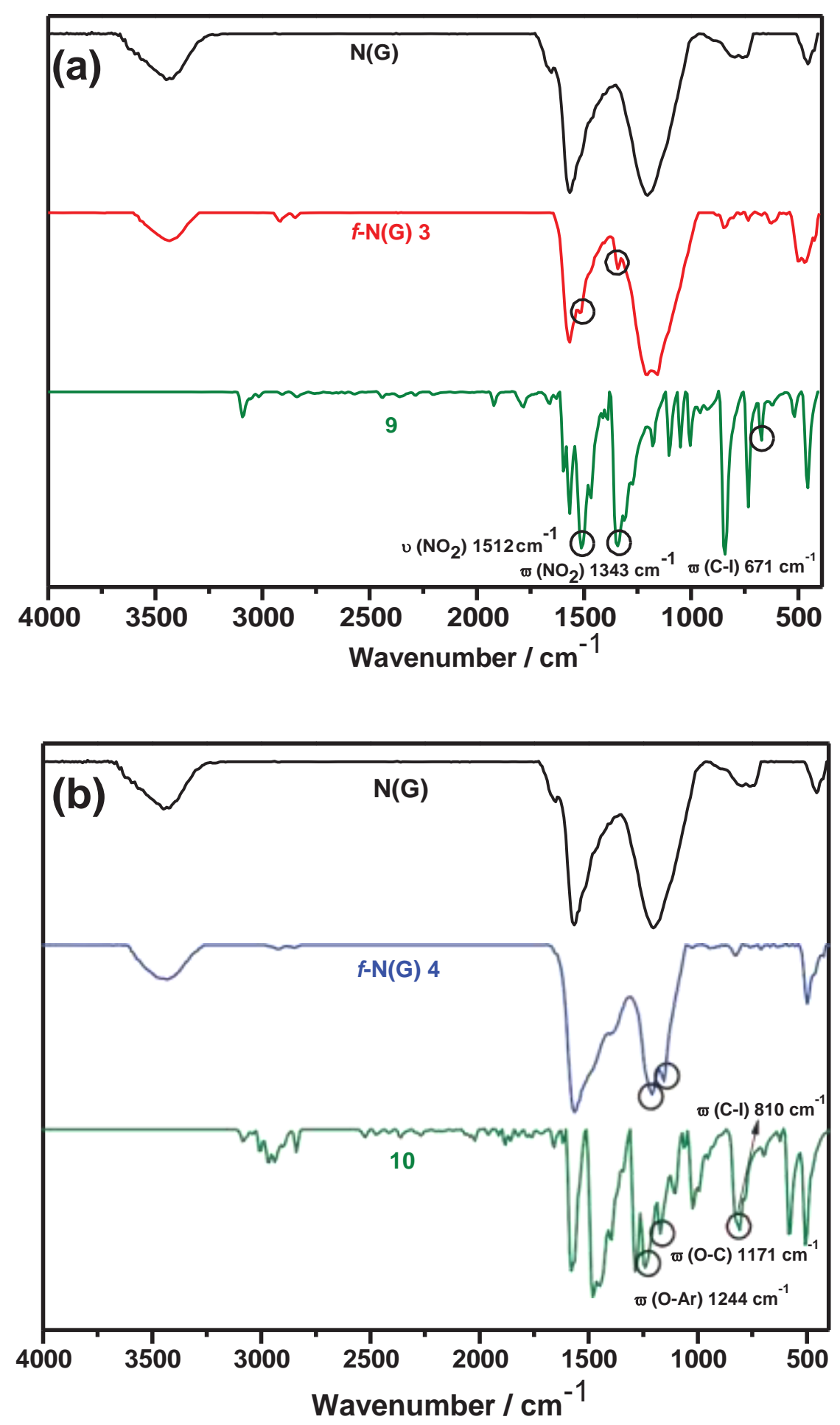

Figure S6. FT-IR spectra of (a) $\mathrm{N}(\mathrm{G})$ compared to final hybrid $\boldsymbol{f}$-N(G) 3 and the corresponding iodo-aryl derivative 9 and (b) $\mathbf{N}(\mathbf{G})$ compared to final hybrid $\boldsymbol{f}-\mathbf{N}(\mathbf{G}) \mathbf{4}$ and the corresponding iodine aryl derivative $\mathbf{1 0}$. 
Table S1. Binding energy $(\mathrm{eV})$ of the core-level atoms of $\mathrm{B}(\mathrm{G})$ samples

\begin{tabular}{|c|c|c|c|c|c|c|c|c|c|c|c|c|}
\hline & $\mathrm{B} 1 \mathrm{~s} / \mathrm{B}$ & $\mathrm{E}(\mathrm{eV})$ & $\mathrm{C} 1 \mathrm{~s} / \mathrm{BE}$ & & & & O1s BE & & & N1s BE & & \\
\hline Sample & $\mathrm{BC}_{3}$ & $\mathrm{BC}_{2} \mathrm{O} / \mathrm{BCC}$ & ${ }^{2} \mathrm{C} / \mathrm{C}-\mathrm{B}$ & $\mathbf{s p}^{3} \mathbf{C}$ & $\mathrm{C}-\mathrm{O} / \mathrm{C}-\mathrm{N}$ & $\mathrm{C}=\mathrm{O}$ & $\mathrm{O}=\mathrm{C}$ & O ad.* & O-C & N-C & $\mathrm{NH}_{2}{ }^{* *}$ & $\mathrm{NO}_{2}$ \\
\hline $\mathbf{B}(\mathbf{G})$ & $\begin{array}{l}191.1 \\
(45)\end{array}$ & $\begin{array}{r}192.7 \\
(55)\end{array}$ & $\begin{array}{r}284.6 \\
(70)\end{array}$ & $\begin{array}{l}285.5 \\
(21)\end{array}$ & $\begin{array}{c}286.3 \\
(9)\end{array}$ & - & $\begin{array}{r}530.7 \\
(19)\end{array}$ & $\begin{array}{c}532.6 \\
(56)\end{array}$ & $\begin{array}{l}533.9 \\
(25)\end{array}$ & - & - & - \\
\hline$f-\mathbf{B}(\mathbf{G}) \mathbf{1}$ & $\begin{array}{c}190.9 \\
(55)\end{array}$ & $\begin{array}{l}192.7 \\
(45)\end{array}$ & $\begin{array}{l}284.6 \\
(62)\end{array}$ & $\begin{array}{c}285.5 \\
(25)\end{array}$ & $\begin{array}{c}286.6 \\
(11)\end{array}$ & $\begin{array}{c}288.5 \\
(2)\end{array}$ & $\begin{array}{r}531.4 \\
(30)\end{array}$ & $\begin{array}{l}533 \\
(42)\end{array}$ & $\begin{array}{l}534 \\
(28)\end{array}$ & - & - & - \\
\hline$f-B(G) 2$ & $\begin{array}{c}190.9 \\
(57)\end{array}$ & $\begin{array}{r}192.7 \\
(43)\end{array}$ & $\begin{array}{c}284.7 \\
(66)\end{array}$ & $\begin{array}{l}285.7 \\
(20)\end{array}$ & $\begin{array}{l}286.8 \\
(11)\end{array}$ & $\begin{array}{c}288.4 \\
(3)\end{array}$ & $\begin{array}{r}531.6 \\
(58)\end{array}$ & - & $\begin{array}{r}533.1 \\
(42)\end{array}$ & $\begin{array}{c}399.6 \\
(43)\end{array}$ & $\begin{array}{c}400.1 \\
(36)\end{array}$ & $\begin{array}{l}405.9 \\
(21)\end{array}$ \\
\hline
\end{tabular}

* This signal is due to the adsorbed oxygen species. ${ }^{3}$

** This signal is associated with the reduction of the nitro group to amine group by X-ray irradiation in the XPS measurement. ${ }^{4}$ 
ChemComm

Table S2. Composition of atomic ratios of $\mathrm{B}(\mathrm{G})$ samples determined from the XPS survey spectra.

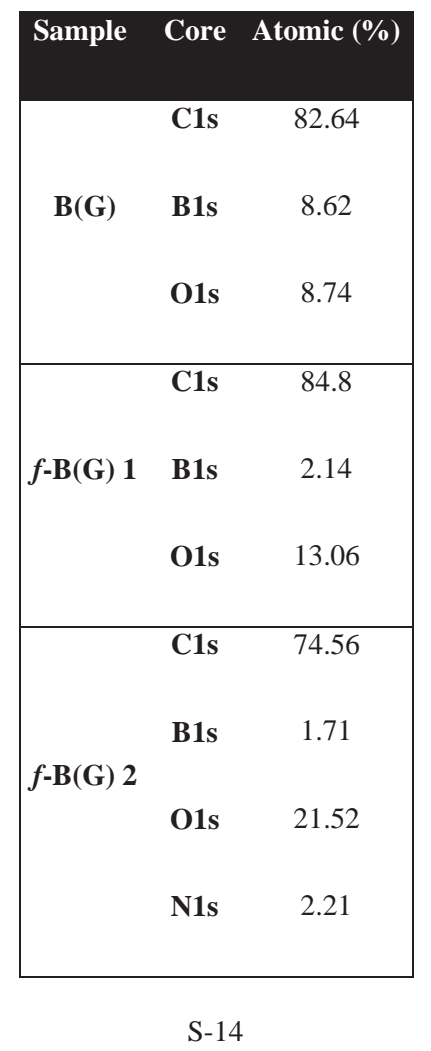


Table S3. Raman G shift based on TGA functionalization in $f-\mathbf{N}(\mathbf{G})$ hybrids 3-4.

\begin{tabular}{|c|c|c|}
\hline Sample & TGA weight loss (\%) RAMAN G band $\left(\mathbf{c m}^{-1}\right)$ \\
\hline $\mathbf{N}(G)$ & 10.3 & 1586 \\
\hline $\boldsymbol{f}$-N(G) 3a & 30.7 & 1588 \\
\hline $\boldsymbol{f}$-N(G) 3b & 48 & 1597 \\
\hline $\boldsymbol{f}$-N(G) 4a & 21.3 & 1584 \\
\hline $\boldsymbol{f}$-N(G) 4b & 39.1 & 1581 \\
\hline
\end{tabular}


Table S4. Binding energy $(\mathrm{eV})$ of the core-level atoms of $\mathrm{N}(\mathrm{G})$ samples

\begin{tabular}{|c|c|c|c|c|c|c|c|c|c|c|c|}
\hline & \multicolumn{4}{|c|}{$\mathrm{C} 1 \mathrm{~s} / \mathrm{BE}(\mathrm{eV})$} & \multicolumn{3}{|c|}{$\mathrm{O} 1 \mathrm{~s} \mathrm{BE}(\mathrm{eV})$} & \multicolumn{4}{|c|}{ N1s BE (eV) } \\
\hline Sample & $\mathbf{s p}^{2} \mathrm{C}$ & $\mathrm{sp}^{3} \mathrm{C}$ & $\mathrm{C}-\mathrm{O} / \mathrm{C}-\mathrm{N}$ & $\mathrm{C}=\mathrm{O}$ & $\mathrm{O}=\mathrm{C}$ & O ad.* & $\mathrm{O}-\mathrm{C}$ & Pyridinic N & Pyrrolic N & Quaternary N & $\mathrm{NO}_{2}$ \\
\hline $\mathbf{N}(\mathbf{G})$ & $\begin{array}{c}284.8 \\
(68)\end{array}$ & - & $\begin{array}{c}286.2 \\
(23)\end{array}$ & $\begin{array}{c}288.0 \\
(5)\end{array}$ & $\begin{array}{c}531.5 \\
(38)\end{array}$ & $\begin{array}{c}532.6 \\
(33)\end{array}$ & $\begin{array}{c}533.8 \\
(32)\end{array}$ & $\begin{array}{c}398.2 \\
(49)\end{array}$ & $\begin{array}{c}400.2 \\
(36)\end{array}$ & $\begin{array}{c}401.8 \\
(15)\end{array}$ & - \\
\hline$f-\mathbf{N}(\mathbf{G}) 3 \mathbf{a}$ & $\begin{array}{c}284.8 \\
(74)\end{array}$ & - & $\begin{array}{c}286.2 \\
(17)\end{array}$ & $\begin{array}{c}287.8 \\
(6)\end{array}$ & $\begin{array}{c}531.4 \\
(32)\end{array}$ & $\begin{array}{c}532.6 \\
(36)\end{array}$ & $\begin{array}{c}533.8 \\
(32)\end{array}$ & $\begin{array}{c}398.2 \\
(28)\end{array}$ & $\begin{array}{c}400.1 \\
(40)\end{array}$ & $\begin{array}{c}401.8 \\
(18)\end{array}$ & $\begin{array}{c}406.2 \\
(14)\end{array}$ \\
\hline$f-\mathbf{N}(\mathbf{G}) 3 \mathrm{~b}$ & $\begin{array}{c}284.8 \\
(72)\end{array}$ & - & $\begin{array}{c}286.2 \\
(22)\end{array}$ & $\begin{array}{c}287.8 \\
(6)\end{array}$ & $\begin{array}{c}531.4 \\
(39)\end{array}$ & $\begin{array}{c}532.6 \\
(33)\end{array}$ & $\begin{array}{c}533.8 \\
(28)\end{array}$ & $\begin{array}{c}398.2 \\
(20)\end{array}$ & $\begin{array}{c}400.1 \\
(43)\end{array}$ & $\begin{array}{c}401.8 \\
(18)\end{array}$ & $\begin{array}{c}406.1 \\
(19)\end{array}$ \\
\hline$f-\mathbf{N}(\mathbf{G}) 4 \mathbf{a}$ & $\begin{array}{c}284.8 \\
(74)\end{array}$ & $\begin{array}{c}285.2 \\
(4)\end{array}$ & $\begin{array}{c}286.2 \\
(18)\end{array}$ & $\begin{array}{c}287.8 \\
(4)\end{array}$ & $\begin{array}{c}531.4 \\
(39)\end{array}$ & $\begin{array}{c}532.6 \\
(37)\end{array}$ & $\begin{array}{c}533.8 \\
(24)\end{array}$ & $\begin{array}{c}398.2 \\
(33)\end{array}$ & $\begin{array}{c}400.1 \\
(41)\end{array}$ & $\begin{array}{c}401.8 \\
(26)\end{array}$ & - \\
\hline$f-\mathrm{N}(\mathrm{G}) 4 \mathrm{~b}$ & $\begin{array}{c}284.8 \\
(70)\end{array}$ & $\begin{array}{c}285.2 \\
(6)\end{array}$ & $\begin{array}{c}286.2 \\
(19)\end{array}$ & $\begin{array}{c}287.8 \\
(5)\end{array}$ & $\begin{array}{c}531.4 \\
(41)\end{array}$ & $\begin{array}{c}532.6 \\
(33)\end{array}$ & $\begin{array}{c}533.8 \\
(26)\end{array}$ & $\begin{array}{c}398.2 \\
(31)\end{array}$ & $\begin{array}{c}400.1 \\
(46)\end{array}$ & $\begin{array}{c}401.8 \\
(23)\end{array}$ & - \\
\hline
\end{tabular}

* This signal is due to the adsorbed oxygen species. 
Table S5. Conductivity values of $\mathrm{B}(\mathrm{G})$ and $\mathrm{N}(\mathrm{G})$ samples.

\begin{tabular}{|c|c|}
\hline Sample & Conductivity (S/m) \\
\hline $\mathbf{B}(\mathbf{G})$ & 1.15 \\
\hline $\boldsymbol{f}$-B(G) 1 & 1.10 \\
\hline $\boldsymbol{f}$-B(G) 2 & 0.52 \\
\hline $\mathbf{N}(\mathbf{G})$ & 357.14 \\
\hline $\boldsymbol{f}$-N(G) 3a & 71.94 \\
\hline $\boldsymbol{f}$-N(G) 3b & 18.15 \\
\hline $\boldsymbol{f}$-N(G) 4a & 48.08 \\
\hline $\boldsymbol{f}$-N(G) 4b & 20.51 \\
\hline
\end{tabular}



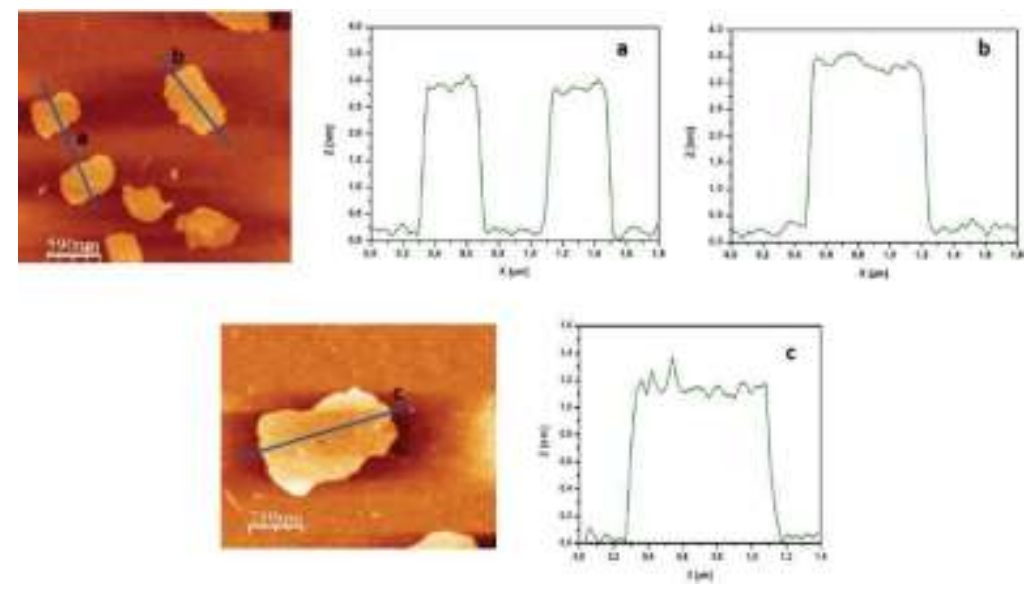

Figure S7. AFM topographic images of $\mathrm{B}(\mathrm{G})$ starting material on a $\mathrm{SiO}_{2}$ surface with height profiles showing a height increment of ca. $3 \mathrm{~nm}$ (a-b) and ca. $1.2 \mathrm{~nm}$ (c).

a)

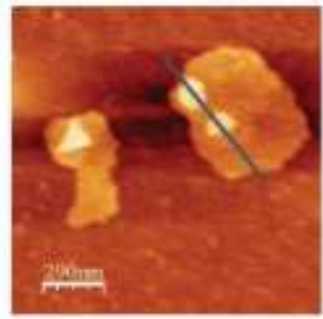

b)

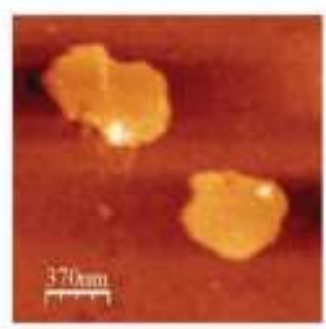

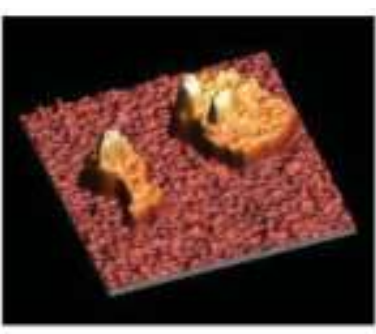
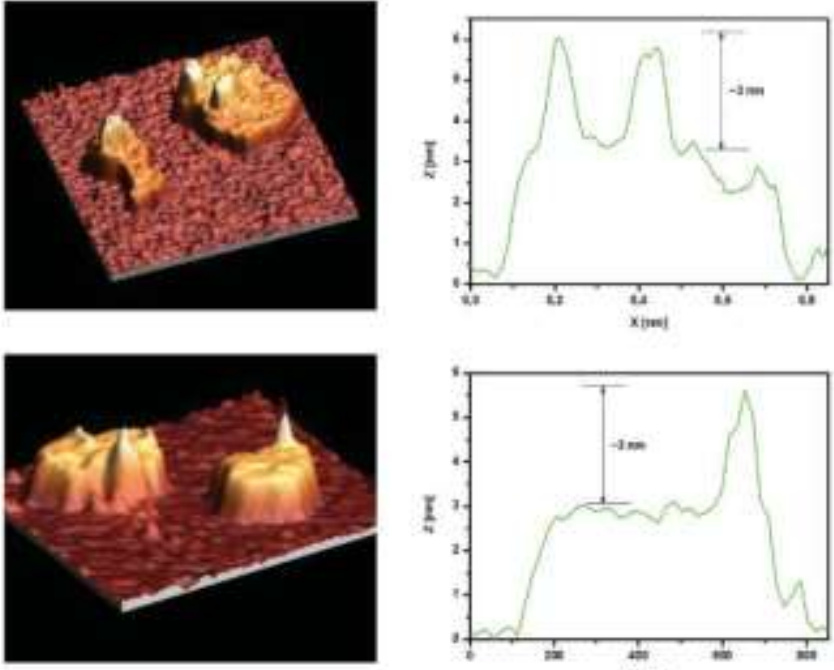

Figure S8. 2D and 3D AFM images of $\boldsymbol{f}$-B(G) materials and height profile analysis showing an increase of $\sim 3 \mathrm{~nm}$; a) $\boldsymbol{f}$-B(G) 1 and b) $\boldsymbol{f}$-B(G) 2 . 
a)
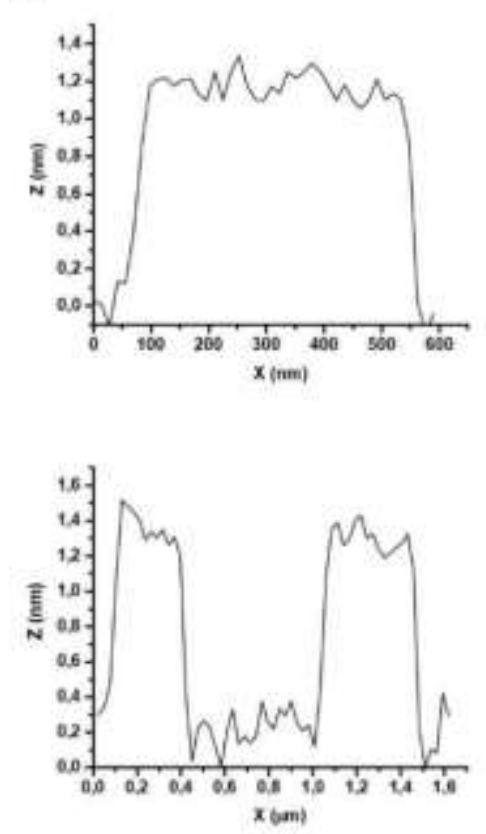
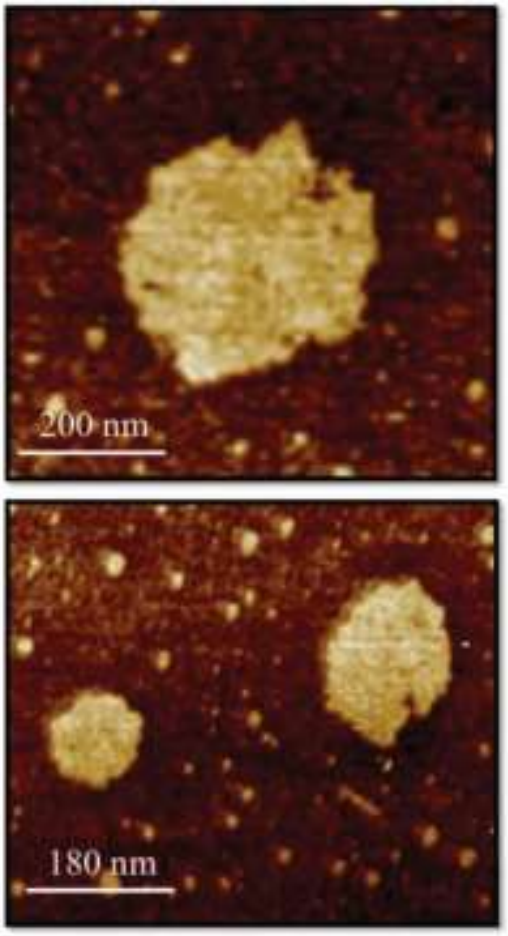

Figure S9. AFM topographic images of $\mathrm{N}(\mathrm{G})$ starting material on $\mathrm{SiO}_{2}$ surface with height profiles showing a height increment of ca. $1.2 \mathrm{~nm}$. 

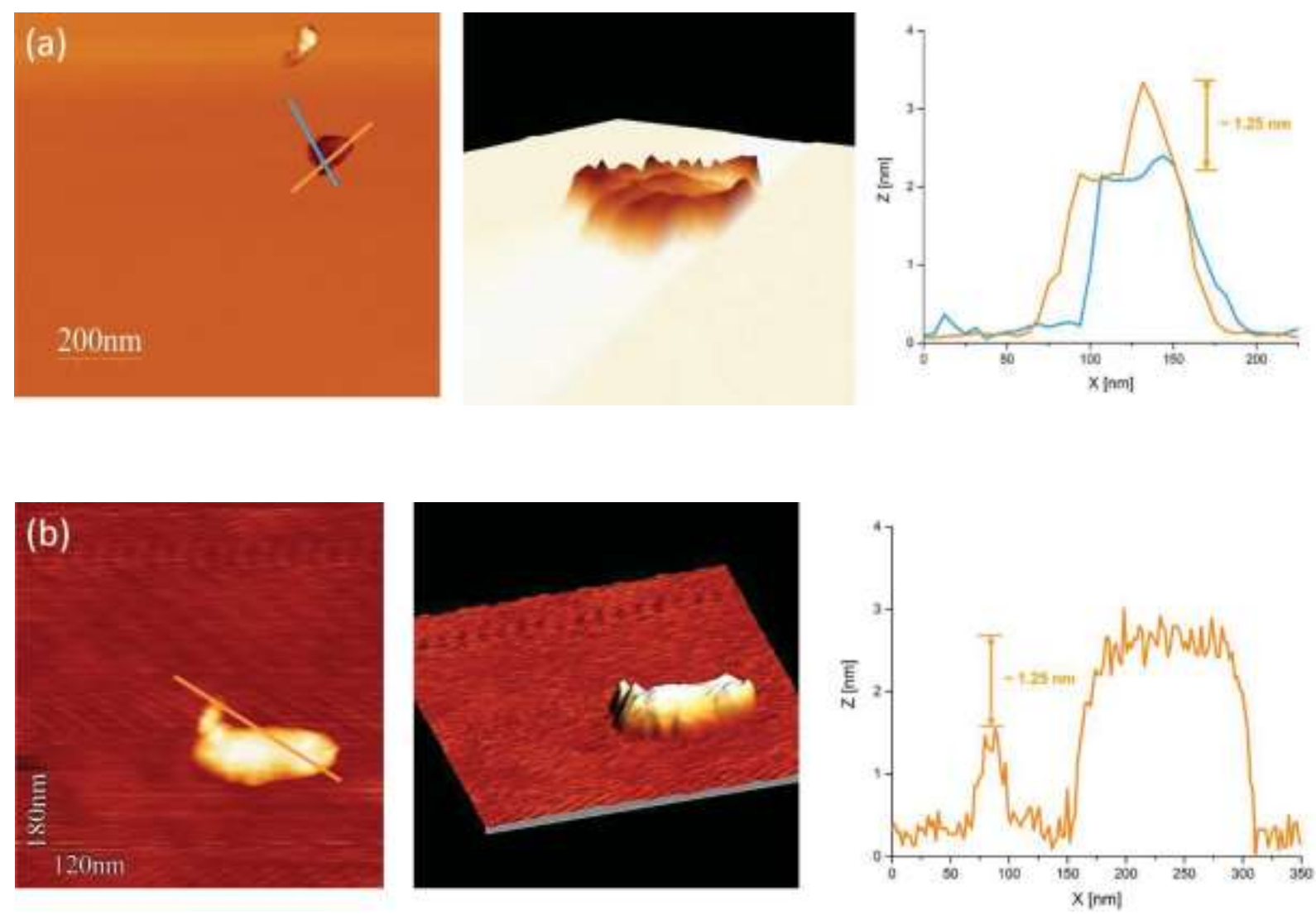

Figure S10. 2D and 3D AFM images of functionalized N(G) materials and height profile analysis showing an increase of $\sim 1.25 \mathrm{~nm}$. (a) $f-\mathbf{N}(\mathbf{G}) 3 \mathbf{b}$; (b) $f-\mathbf{N}(\mathbf{G}) \mathbf{4 b}$. 

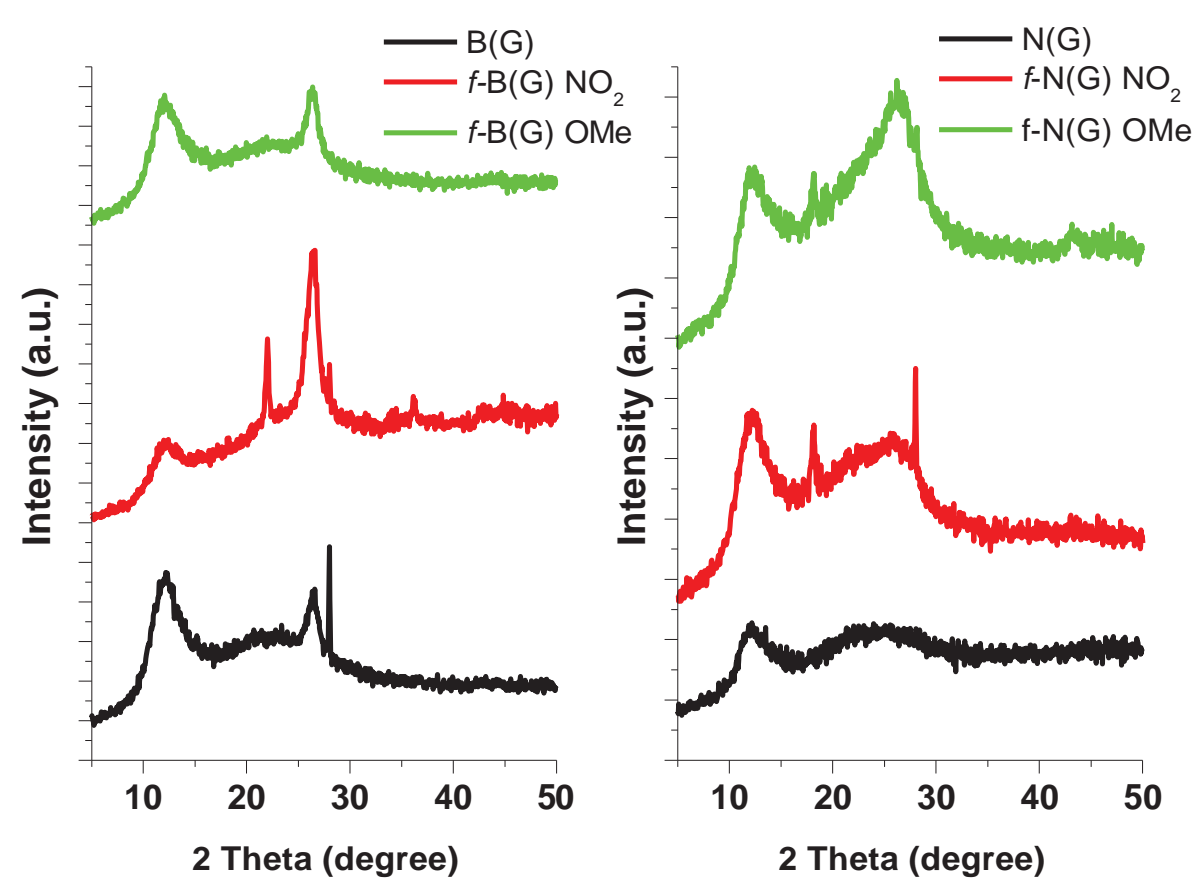

Figure S11. X-ray diffraction patterns of (left) B-doped graphene samples and (right) N-doped graphene samples. 


\section{Preparation of graphene electrodes materials:}

\section{Sample preparation}

Preparation of graphene electrode: $2 \mathrm{mg}$ of each sample (f-doped graphenes 1-4) were dispersed in $2 \mathrm{~mL}$ of $N, N$-dimethylformamide (DMF) and sonicated for $10 \mathrm{~min}$. After this time, the stable ink (see Figure S12) was deposited slowly by drop-coating on an acid-treated quartz substrate heated on a hotplate at $80{ }^{\circ} \mathrm{C}$ (see Figure S13). After complete drying, the corners of the graphene electrode $\left(1 \times 1 \mathrm{~cm}^{2}\right)$ were covered with conductive silver ink.

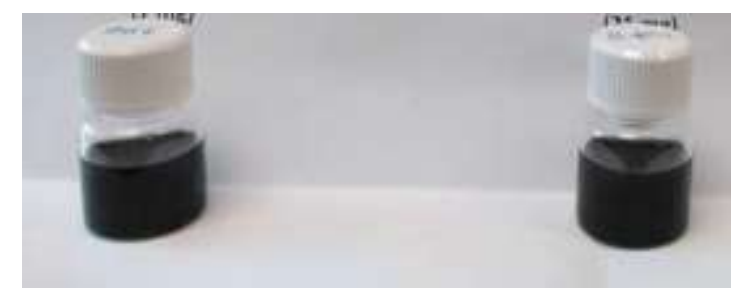

Figure S12. Inks prepared with $\mathrm{B}(\mathrm{G})$ (left) and $\boldsymbol{f}$-B(G) 2 (right) inn $\mathrm{DMF}(1 \mathrm{mg} / \mathrm{mL})$.

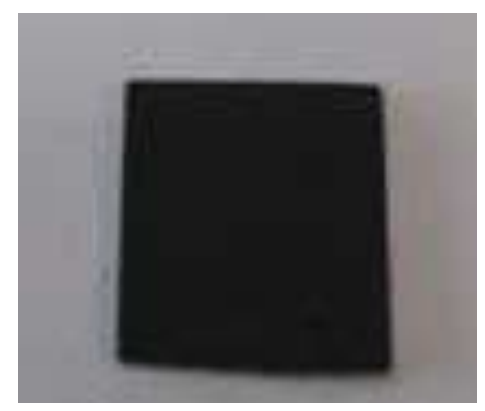

Figure S13. Layer of $\mathrm{B}(\mathrm{G})$ deposited on a quartz substrate.

\section{Hall effect measurements}

To determine the sheet resistance of the samples, according to the Van Der Pauw method, ${ }^{5}$ several measurements were made between different contacts. In each measurement, a current (I) was forced through the sample between two neighbouring contacts while the voltage (V) 
was measured between the other two contacts, see Figure S14 as an example, then the following ratios $R_{A}$ and $R_{B}$ were calculated (equation 1 and equation 2 ):

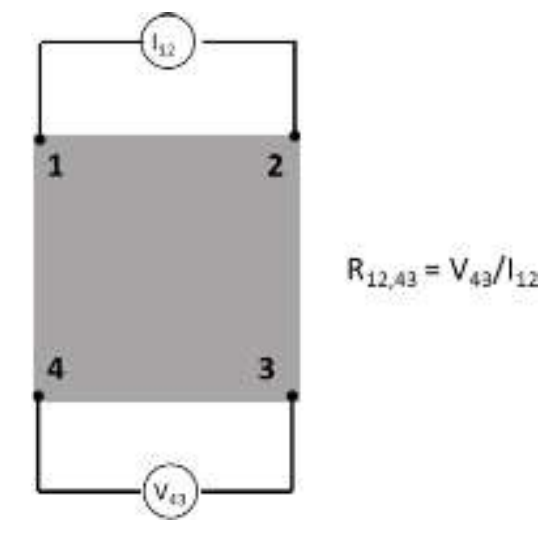

Figure S14. Example of the contact measurement for the determination of the sheet resistence.

$R_{\bar{A}}=\frac{R 21,34+R 12,43+R 43,12+R 34,21}{4}$

$R_{\bar{B}} \frac{R 32,41+R 23,14+R 14,23+R 41,32}{4}$
Equation (1)

Equation (2)

The Van Der Pauw method related $\mathrm{R}_{\mathrm{A}}$ and $\mathrm{R}_{\mathrm{B}}$ with the sheet resistance $\left(\mathrm{R}_{\mathrm{S}}\right)$ by solving equation 3

$\exp \left(-\frac{n \cdot R_{A}}{R_{S}}\right)+\exp \left(-\frac{n \cdot R_{B}}{R_{S}}\right)=1$

Equation (3)

On the other hand, for the calculation of the Hall voltage $\left(V_{H}\right)$, which relates the carrier mobility $\left(\mu_{\mathrm{H}}\right)$, the major carrier concentration $\left(\mathrm{n}_{\mathrm{S}}\right)$ and the conductivity semiconductor type $(\mathrm{N}$ or $\mathrm{P})$, a similar procedure was followed, but the voltage was measured after appling a magnetic field perpendicular to the sample. The combination of the current flow (I) and the magnetic field caused a transverse current, thus producing a potential across the device $\left(\mathrm{V}_{\mathrm{H}}\right)$. In addition, this 
voltage was measured upon applying positive $(+B)$ and negative (-B) magnetic field. Finally, the Hall voltage was calculated using the following equation:

$V_{H}$

$=\frac{\left(V_{24 P, / 13}-V_{24 N, / 13}\right)+\left(V_{42 P, / 31}-V_{42 N, / 31}\right)+\left(V_{13 P, / 42}-V_{13 N, / 42}\right)+\left(V_{31 P, / 24}-V_{31 N, / 24}\right)}{8}$

Once $\mathrm{V}_{\mathrm{H}}$ had been calculated, the mobility and sheet density of the major carrier $\left(\mathrm{n}_{\mathrm{S}}\right)$ were obtained from equations 5 and 6:

$$
\begin{array}{cc}
n_{s}=\frac{I \cdot B}{q \cdot V_{H}} & E q .5 \\
\mu_{H}=\frac{V_{H}}{R_{S} \cdot I \cdot B} & E q .6
\end{array}
$$

Where I is the current applied (A), B is the magnetic field (gauss) and q the elementary charge $\left(1.602 \cdot 10^{-19}\right.$ Coulombs).

All samples were connected using the sample holder SPCB-1 Spring Clip Board from Microworld and a Keithley 2450 potentiostat was used as the current and voltage source. The magnetic field used in the experiment was $0.695 \mathrm{~T}$.

\section{References}

1. L.Niu, Z. Li, W. Hong, J. Sun, Z. Wang, L. Ma, J. Wang, S. Yang, Electrochim. Acta 2013, 108, 666.

2 Q. Xu, X. Jiang, W. Zhu, C. Chen, G. Hu, Q. Li, Arab. J. Chem., 2016, 9, 721.

3 Y. Yan, S. Yan, Z. Yu, Z. Zou, Chem.Cat.Chem. 2019, 11, 1.

4 E. Bekyarova, M. E. Itkis, P. Ramesh, C. Berger, M. Sprinkle, W. A. de Heer and R. C. Haddon, J. Am. Chem. Soc., 2009, 131, 1336.

5 L. J. v. d. Pauw, Philips Tech. Rev. 1958, 20, 220. 
Page 1 of 63

S-1 